Review Article

\title{
Scanning Electron Microscopy and Atomic Force Microscopy: Topographic and Dynamical Surface Studies of Blends, Composites, and Hybrid Functional Materials for Sustainable Future
}

\author{
Joanna Rydz $\mathbb{1},{ }^{1}$ Alena Šišková, ${ }^{2}$ and Anita Andicsová Eckstein ${ }^{3}$ \\ ${ }^{1}$ Centre of Polymer and Carbon Materials, Polish Academy of Sciences, 41-800 Zabrze, Poland \\ ${ }^{2}$ Institute of Materials and Machine Mechanics, Slovak Academy of Sciences, 84513 Bratislava, Slovakia \\ ${ }^{3}$ Polymer Institute, Slovak Academy of Sciences, 84541 Bratislava, Slovakia \\ Correspondence should be addressed to Joanna Rydz; jrydz@cmpw-pan.edu.pl
}

Received 2 May 2019; Revised 6 June 2019; Accepted 11 June 2019; Published 10 July 2019

Academic Editor: Candido Fabrizio Pirri

Copyright (c) 2019 Joanna Rydz et al. This is an open access article distributed under the Creative Commons Attribution License, which permits unrestricted use, distribution, and reproduction in any medium, provided the original work is properly cited.

Microscopic techniques are often used in material science, enabling the assessment of the morphology, composition, physical properties, and dynamic behaviour of materials. The review focuses on the topographic and dynamical surface studies of (bio) degradable polymers, in particular aliphatic polyesters, the most promising ones. The (bio)degradation process promotes physical and chemical changes in material properties that can be characterised by microscopic techniques. These changes occurring both under controlled conditions as well as in the processing stage or during use indicate morphological and structural transformations resulting from the deterioration of the material and have a significant impact on the characteristic of materials used in many applications, for example, for use as packaging.

\section{Introduction}

Knowledge of the relationships between structure, properties, function, and performance is essential for prospective safe applications of (bio)degradable and/or biobased polymers in the areas of human health and the environment. The study of the physical and technical basis of the latest developments in the above areas is based quite often on microscopic techniques that are also used in a various industrial applications, including topographic and dynamical surface studies of many materials including polymers. Fundamental research and applied research in emerging areas of applications in nanotechnology, interfacial science and engineering, advanced production, catalysis, bioengineering, bioinspired synthesis, green production routes, sensing, and actuation are often also based on microscopic techniques. Particular emphasis should be placed on environmentally friendly blends, composites, and hybrid materials from renewable resources without adverse environmental impact, with a short global carbon lifecycle, with green production routes and/or suitable to recycle, materials based on natural, renewable, and synthetic polymers for a sustainable future [1-3].

In recent years, the focus has been taken on the development of novel atomic force microscope (AFM) and scanning electron microscope (SEM) based methods. The SEM and AFM are powerful characterisation tools in polymer science, capable of revealing surface structures. SEM provides a three-dimensional (3D) image with high resolution and is used to characterise the morphology of the sample surface, particle size, microorganism, and fragments. Energy-dispersive (EDS) detector can additionally provide semiqualitative and semiquantitative information on elemental analysis of the surface (topochemical data) and identification of additives and impurities to detect contamination (residues) as well as determine the origin of sample damage [4]. SEM is a powerful visualisation tool used in material science, including in the field of polymer 
sciences. Due to the high lateral resolution, large depth of focus, and the facility for X-ray microanalysis, it provides a consistent image of the polymer blends and composites morphology as a nonuniform structure characterised by polymer variable thickness and variable density. For SEM analysis, the surface of nonconductive samples must be coated with a thin layer of gold or platinum. Sometimes, surface pretreatment is carried out by ion sputtering or chemical etching to reveal structural details. In addition, brittle fracture (in liquid nitrogen) can provide information about the internal morphology of polymer matrix. SEM micrographs show that polymer blends and composites can have different surface features and heterogeneous local density of chemical components. SEM images also show surface defects such as cracks, etching residues, differential swelling, depressions, and perforations [5]. However, SEM drawback is that during imaging, the electron beam may permanently damage the observed sample. Degradation, an undesirable effect, can alter or destroy details and consequently change the results and conclusions [6]. By means of AFM technique, in addition to topography imaging at the nanometre scale, the phase imaging mode is actively involved in the mapping of surface heterogeneity of the blends, composites, and hybrid materials because the phase response of the cantilever is sensitive to the surface properties, such as adhesiveness, friction, electrical forces, capacitance, magnetic forces, conductivity, viscoelasticity, surface potential, and resistance without need for sample preparation or vacuum environment $[7,8]$. It has been shown that AFM is able to provide both qualitative and semiquantitative information on the deterioration and ageing of materials during degradation [9]. In phase mode imaging, different samples exhibit different interactions with the AFM tip, so the phase shift changes. The properties of the sample affected by interactions with the AFM tip include friction, adhesion, and high elasticity. Using phase mode, images show differences between the local regions on the sample, and this mood is also useful for testing the consistency of coatings and for displaying cracks and other degradation features [10].

Analysis of polymer blends and composites morphology and surface changes (erosion) using AFM and SEM techniques gives a lot of information about various processes and phenomena. The use of a microscope to monitor a number of aspects of the surface degradation of polymer blends and composites in various selected degradation environments allows to track the relationship between surface topography and degradation patterns of materials and provide reliable parameters for predicting of long-term degradation. Likewise, miscibility of blends is one of the most important factors affecting the properties of polymer materials. The surface structure and morphology of (bio)degradable polymer blends have a great impact on the degradation process. Moreover, microscopic observation is a powerful tool to detect 3D printing defects and downstream processing problems, which can also affect the course of degradation of printed items [11]. Farther imaging techniques, such as SEM and AFM, have been developed to observed materials of submicron size, so they can be used to determine microscopic characteristics of nanomaterials such as shape, size, surface morphology, crystal structure, and dispersion and are an important part of determining phase purity, electronic transition plasmonic character, atomic environment and surface charge, etc. [12, 13]. Also, microscopic examination of electrospun (bio)degradable polymers allows understanding the relationships between processing parameters, morphology of the samples, and their properties. The formed mats have unique characteristics such as high porosity, surface area to volume ratio, permeability, porosity, stability, ease of functionalisation, and excellent mechanical performance $[14,15]$.

The development of (bio)degradable polymeric materials for many new advanced applications is of great importance not only for usable reasons, but also from the point of environmental protection and sustainable development. The efficient use of these polymers requires basic research necessary to determine the relationship between the structure of such materials, properties, and mechanism of degradation. Therefore, the following overview presents the most important issues in the testing of the behaviour of (bio) degradable polymeric materials in various environments using surface imaging techniques, which have not been presented in one review so far. Microscopic techniques are a tool for studying changes in the surfaces of materials under investigation during various processes and assessing microdamage, such as crack propagation, grain size change, and capability, which allows to provide qualitative and semiquantitative information on degradation and ageing. They are also a sensitive tool to detect the deterioration of the materials tested and characterise mechanisms of the blends and composites reinforcement.

\section{Microscopic Investigation of Eco-Friendly Polymer Blends and Composites}

2.1. Ageing and Degradation Processes. AFM allows for a microdestructive quantitative distinction between the initial and the final stage of degradation [4]. The polymers before degradation generally have a fairly flat and smooth surface. During degradation, the surface becomes rougher. The dissolution of degradation products and erosion usually create cracks and pores which cause an increase of roughness. Small cracks, formed by water absorption (in case of hydrolytic degradation in aqueous media) or simply erosion of the polymer, increase as contact with water leads to hydrolysis, and locally produced acids catalyse degradation and cause polymer dissolution inside the pores. The depth and/or the number of pores in the surface increased with time, conditions, and degradation media. The surface erosion depends also on the solubility of the low-molar-mass degradation products [16].

Under natural conditions (compost and weather conditions) at the beginning of degradation, cracks on the surface of the polymeric material appear, after which the material begins to disintegrate into pieces in accordance with cracks (disintegration). Degradation under natural conditions of the polylactide (PLA) and PLA/PHB (PHB: poly(3-hydroxybutyrate)) blend, as well as their composite 
materials proceeds according to a different mechanism, which reflects the microscopic images. The cracks on the PLA material surface appear, and then the erosion occurred inside deeper part of the material, which indicates a watercatalysed hydrolysis mechanism. For a PLA/PHB blend, the homogeneously licking of the whole surface, layer by layer, is observed, which indicates an enzyme-catalysed hydrolysis mechanism $[8,17,18]$. The degradation of polyesters in a biological environment, including anaerobic and aerobic conditions, activated sludge, public wastefields, and composting facilities, results from enzymatic attack (in the presence of specific enzymes produced by microorganisms such as bacteria and fungi) or simple hydrolysis (watercatalysed cleavage of ester bonds) or both. In contrast to bacterial polyesters, such as polyhydroxyalkanoates (PHAs), which directly undergo biodegradation by many microorganisms present in the environment, the highmolar-mass PLA is colonised by relatively few microorganisms and more frequently takes place the water-catalysed hydrolysis of this material. But in general, for (bio) degradable polymers, the first step of biodegradation under natural and laboratory conditions is a chemical hydrolysis (mainly through random chain scission), which leads to a reduction of molar mass. In the next step, called mineralisation, the oligomers formed are bioassimilated by microorganisms as an energy source [19].

Figure 1 presents SEM micrographs of the surface of the PHA films treated with (i) lipase solution $(0.1 \mathrm{~g} / \mathrm{L})$ under $30^{\circ} \mathrm{C}$

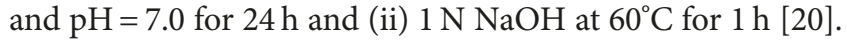

Many microorganisms, such as extracellular $\mathrm{PHB}$ depolymerase, excrete enzymes outside their cell walls. The enzymes first adsorb onto the surface of polymer materials through their substrate-binding domains at the C-terminus and then catalyse the hydrolysis of polymer chains by their catalytic domains at the N-terminus [21]. The enzymes are able to cleave specific bounds in the polymer chain on the surface of the polymer material, which causes the destruction of this material layer by layer (surface erosion, does not occur inside the polymer matrix) (see Figure 1, lipase) [22]. Nonenzymatic hydrolysis of PHAs proceeds from the surface towards the deeper layers. The surface became rougher, and the density of the holes forming on the surface increased (see Figure 1, $\mathrm{NaOH}$ ) [21].

Investigation of biodegradation of PHA/wood composites using SEM in secondary electron mode showed that despite the low-molar-mass loss, which is characteristic in the first stage of biodegradation, when the surface degrades, layer by layer, the surface of plain PHA had a clearly rough surface with dents after 12 months of burial in soil. The surface of PHA composite with $20 \%$ wood was also significantly rougher after soil burial. A network of fungal hyphae filaments has been embedded in the matrix with the presence of spores. The decreases in molar mass of PHA throughout 12 months of soil burial became more severe as the wood content increased [23].

The degradation of PLA and its composites with starch in compost and soil also indicates the process catalysed by enzymes in the case of composites. SEM micrographs (see Figure 2) showed changes in surface morphology (cracks) of
PLA and its composites after degradation in compost and soil for 14 days. (Bio)degradation occurred for all polymer samples tested, but more changes were observed in PLA/ starch (50/50) composite than on pure PLA samples. This means that the addition of starch to PLA resulted in their greater biodegradability. Starch was eroded from the surface of the PLA blends, while for pure PLA, degradation occurred in the deeper part of the polymer, suggesting a preferential mechanism of chemical hydrolysis. Degradation occurred faster in compost than in soil [24].

The EDS detector can be used to identify of additives affecting the course of degradation. It was found that differences in the rate of degradation of PLA/PBAT (PBAT: poly(butylene adipate-co-terephthalate)) blends with a similar content of the PLA component may be due to differences in their thickness and/or the presence of commercial additives used during processing. The results indicated that the presence of talc may interfere with the behaviour of materials towards water and consequently alter their degradation profile. EDS analysis of selected regions of PLA/PBAT blends showed the presence of white inclusions ( $\mathrm{Mg}$ and $\mathrm{Si}$ ) in the polymeric matrix derived from a commercial additive, hydrated magnesium silicate (talc) (see Figure 3) [25].

2.2. Effects of Miscibility. Observation of the surface morphology by AFM can confirm different miscibilities of the polymer material $[8,26]$. The blends with poor miscibility exhibit phase separation of the components, while a homogenous surface morphology is observed for the blend with good miscibility (see Figure 4) [16]. Miscibility and compatibility of polyester blends containing PLA and PHAs, such as $\mathrm{PHB}$ or poly(3-hydroxybutyrate-co-3-hydroxyvalerate) (PHBV) depend on the molar mass and crystallinity of the components, on the blending method and the composition of the blend. The blends are immiscible when the molar mass of components is high [27]. A decrease of molar mass of one of the blend components results in a reduction of the phase separation [28].

The diameter and depth of the pit domain of immiscible blends increased as the poly $([R, S]-3$-hydroxybutyrate $)$ $((R, S)$-PHB) component increased in the blends, as observed by AFM. Only in the blend with good miscibility, the surface was completely smooth. The degree of erosion of the polymeric material is strongly dependent on the blend miscibility of the two components. The poor miscibility of the blend with the largest pit domain before degradation promoted greater roughness of the surface during degradation [16].

The cocontinuous phase structure of polymer blend can be confirmed by means of SEM. SEM was used to analyse the effect of a preparation method on the miscibility of PBAT and poly(hydroxy ether) (PH) of bisphenol A blends and the effect of a nondegradable component $(\mathrm{PH})$ in the degradation of PBAT. A continuous morphology of the 50PBAT/50 PH blend prepared by casting can be observed. This type of morphology was attributed to phase inversion composition. The morphology of $25 \mathrm{PBAT} / 75 \mathrm{PH}$ has a 

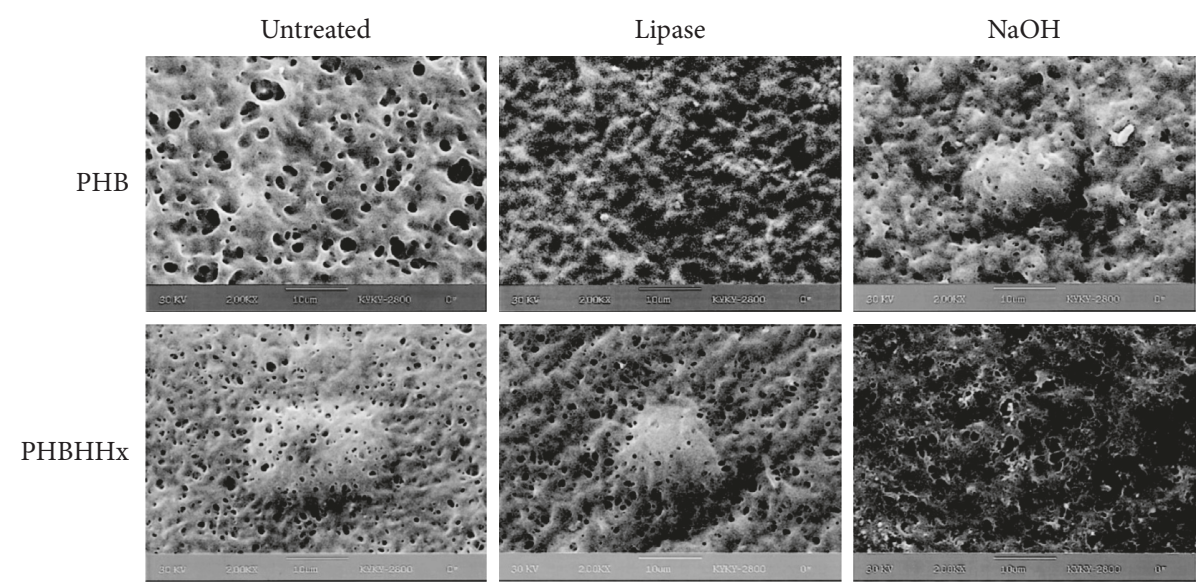

FIGURE 1: SEM micrographs of PHB and poly(3-hydroxybutyrate-co-3-hydroxyhexanoate) (PHBHHx) films before degradation (untreated) and after lipase and $1 \mathrm{~N} \mathrm{NaOH}$ catalysed hydrolysis (adapted with permission from ref. [20]).

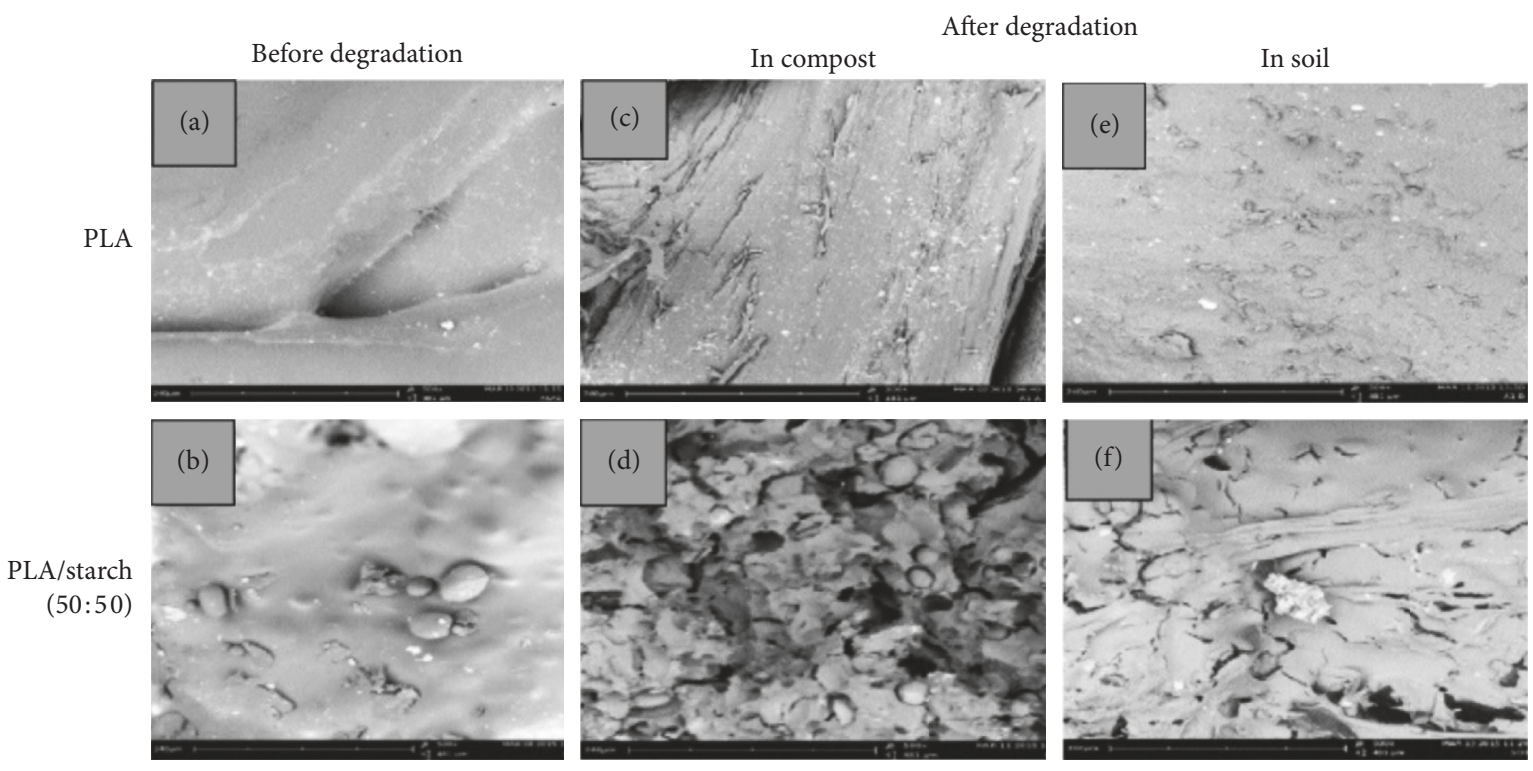

FIGURE 2: SEM images of PLA and PLA/starch (50/50) composite samples surface before degradation (a and b), after degradation in compost ( $c$ and $\mathrm{d}$ ), and after degradation in soil (e and f) for 14 days (adapted with permission from ref. [24]).

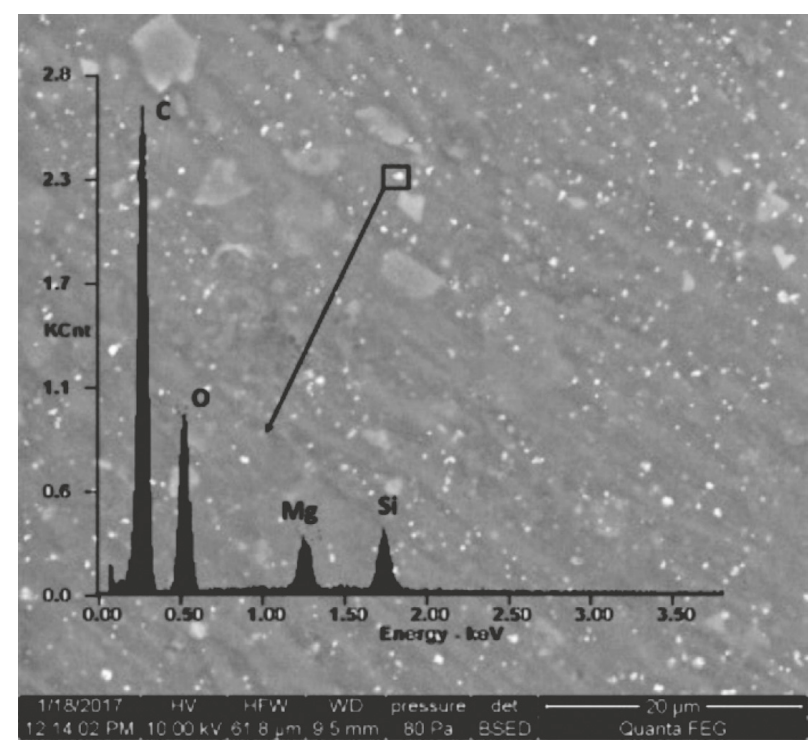

FiguRE 3: SEM-EDS micrograph of PLA/PBAT (40/60) blend surface at a magnification of 2500x (adapted with permission from ref. [25]). 

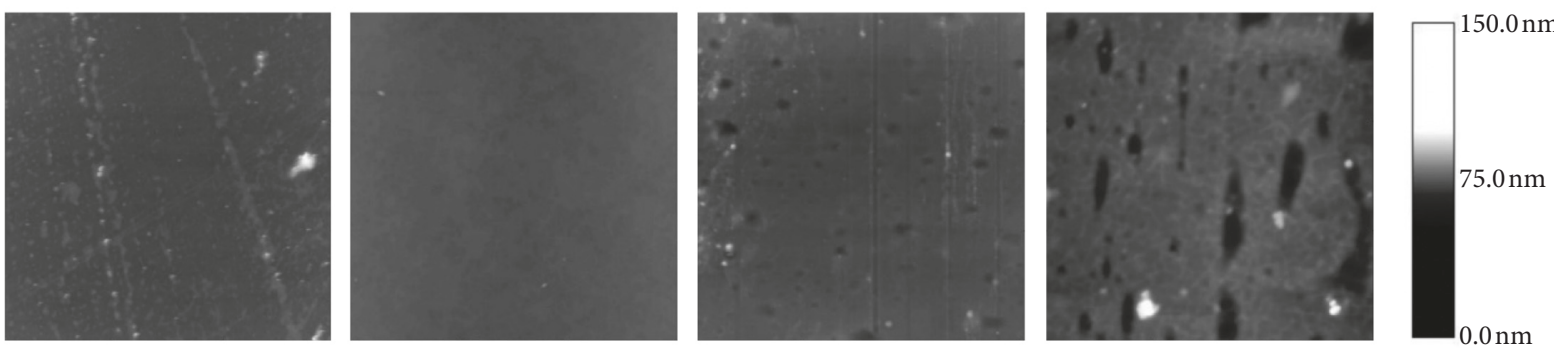

(a)
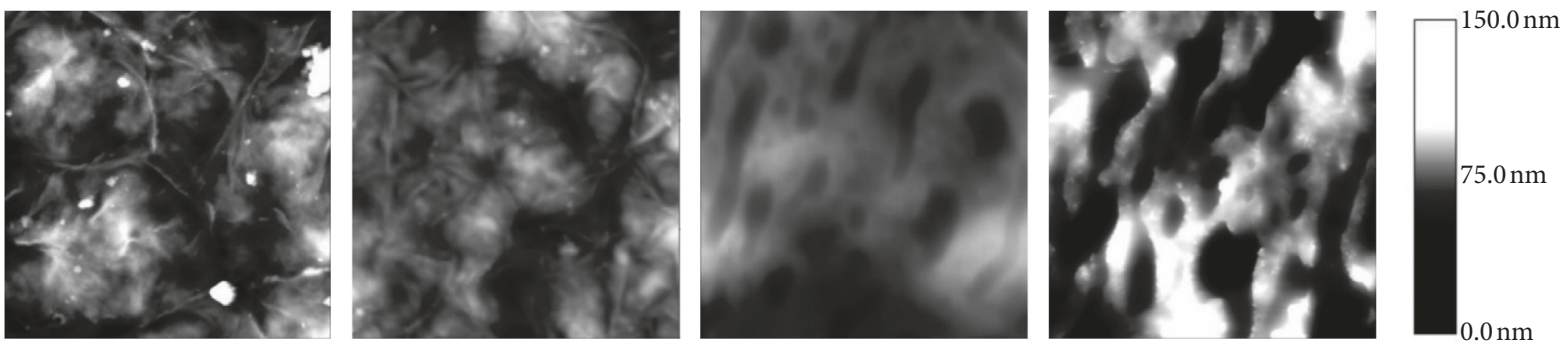

(b)

Figure 4: Selected $6 \times 6 \mu \mathrm{m}$ AFM images of the surface erosion of PLA, 97PLA/3(R,S)-PHB, 91PLA/9(R,S)-PHB, and 85PLA/15(R,S)-PHB blend samples, respectively, before (a) and after (b) 52 weeks of the degradation process in paraffin (adapted with permission from ref. [16]).

biphasic structure: the adhesion between the two components is very good; however, the blend is immiscible. As expected, the rate of degradation decreased with the addition of $\mathrm{PH}[29]$.

The effect of melt viscosity of the two melt blended polymers, PLA and PBAT, on the morphology and mechanical properties of obtained (bio)degradable blends was investigated by means of SEM. Based on the relative melt viscosities of the PLA and PBAT in the processing method, it is possible to calculate the volume fraction in which a cocontinuous phase structure is formed. The SEM image of the fracture surface from the tensile tests for pure PLA exhibited a flat, featureless structure that is typical of brittle fracture. In PBAT/PLA blends with PBAT between 20 and $40 \mathrm{wt} \%$, a cocontinuous phase structure was observed; the fibrils were drawn from the fracture surfaces, which is a common feature of ductile failure. Since PBAT has a much lower yield stress than PLA and undergo plastic deformation at lower stress, these fibrils were caused by a continuous PBAT phase. When PBAT content in the PBAT/PLA blend reached $60 \mathrm{wt} \%$, the continuous PLA phase was no longer visible. Large PLA particles were dispersed in a continuous PBAT phase, and they deboned from the matrix, which caused cracks and flaws at the interface, resulting in relatively poor mechanical properties. When the PBAT content reached $80 \mathrm{wt} \%$, the blend exhibited very ductile behaviour in the tensile test. PLA was still dispersed in the PBAT in the form of particles; however, the particle size was much smaller and the dispersion became much more uniform. The impact of PLA on the mechanical properties was unimportant, and the blend behaved in a similar way to pure PBAT (see Figure 5) [30].
2.3. Three-Dimensional Printing: Defect Detection. 3D printing or additive manufacturing (AM) refers to processes used to create objects in $3 \mathrm{D}$ using digital data of the $3 \mathrm{D}$ model. To form 3D objects with almost any shape or geometry, subsequent layers of material are applied [31]. 3D printing is a valuable alternative to traditional processing methods in the creation of various products, such as scaffolds for regenerative medicine, artificial tissues and organs, electronics, components for the transportation industry, art objects, etc. This technique has demonstrated exceptional capacities for producing complex structures with precisely tailored physical and mechanical properties, biological functionality, and an easily customisable architecture [32].

Subsequent layers may, however, contain structural interruptions or defects that negatively affect the reliability of the $3 \mathrm{D}$ printed object [31]. Also, build direction has a significant effect on the structure and morphology and hence on the properties of elements made using $3 \mathrm{D}$ printing (see Figure 6) [33].

When samples are printed horizontally, upper and underside layers have surfaces with a different characteristic. This is due to the fact that one layer is in contact with the $3 \mathrm{D}$ printer platform. In the case of fused deposition modelling, rapid prototyping technique, the heated thermoplastic polymer filament is extruded from a tip that moves in the $X Y$ plane. The controlled extrusion head deposits the polymer material onto the printer platform, first forming the underside layer. The printer platform is kept at not too high constant temperature (around $65^{\circ} \mathrm{C}$ for polyesters), whereby the thermoplastic material hardens quickly. However, polymeric material is permanently maintained at a constant temperature during printing which can affect properties of 


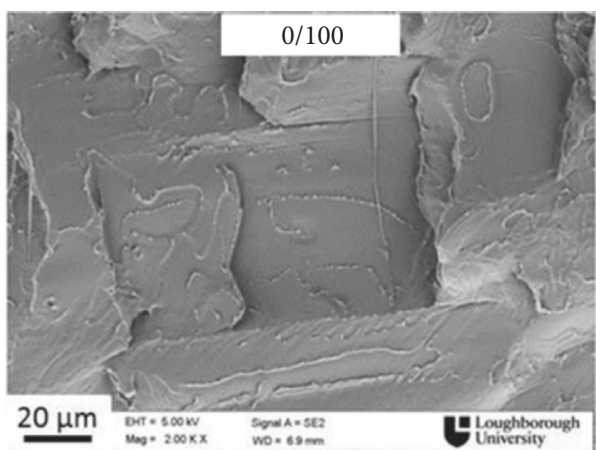

(a)

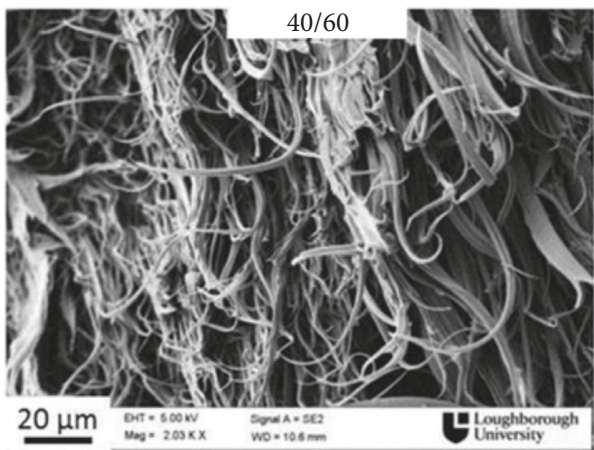

(c)

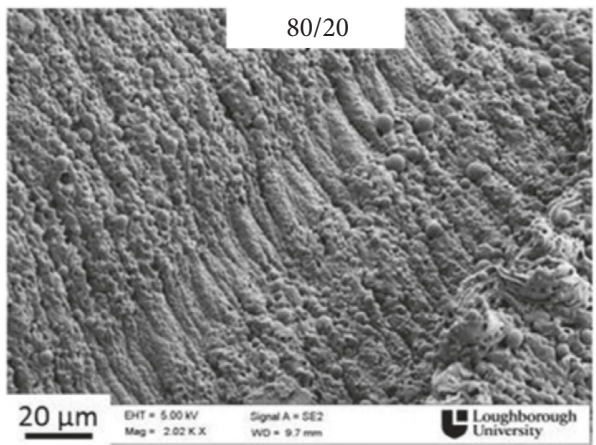

(e)

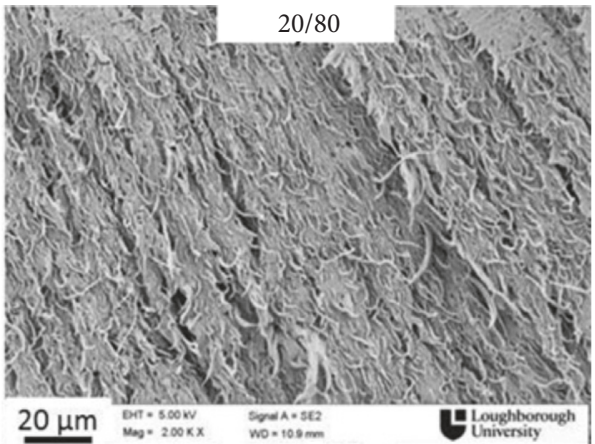

(b)

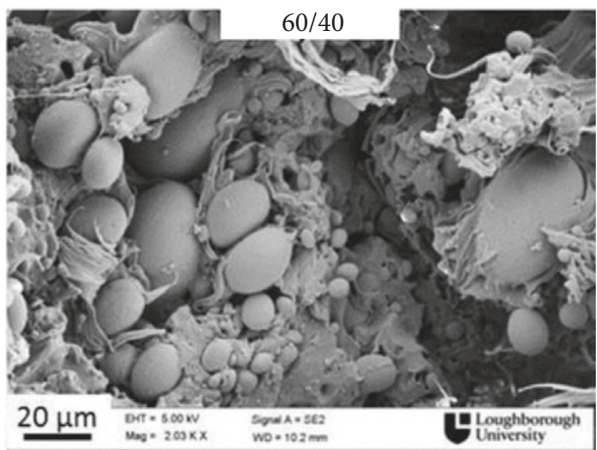

(d)

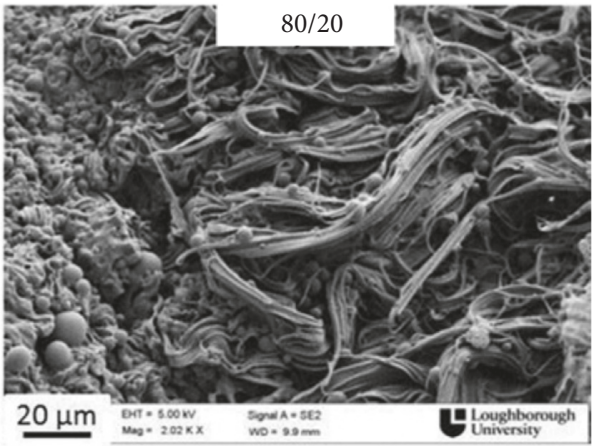

(f)

FIgURE 5: SEM micrographs of fracture surfaces from the tensile tests of PBAT/PLA blends (adapted with permission from ref. [30]).

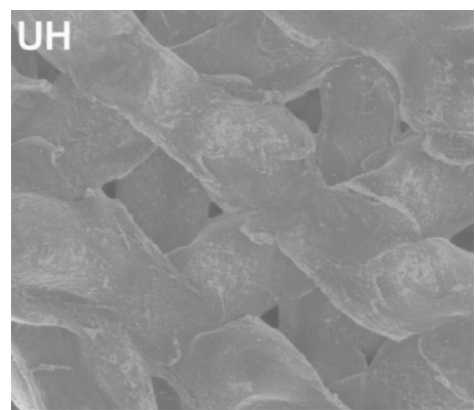

(a)

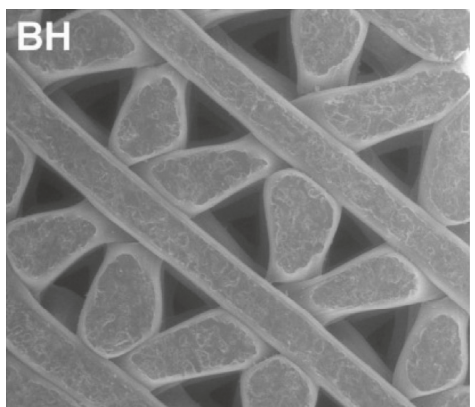

(b)

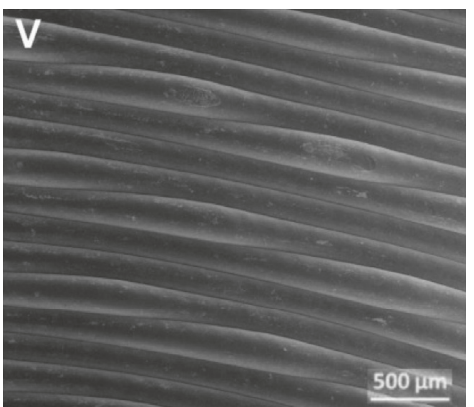

(c)

FiguRE 6: SEM micrographs of upper (UH) and underside $(\mathrm{BH})$ layers of samples surface obtained by $3 \mathrm{D}$ printing in horizontal (H) and vertical (V) directions (adapted with permission from ref. [33]). 
the final element from (bio)degradable polymers, such as PLA or PLA/PHA blend. The extrusion head deposits the material layer by layer in the $Z$-axis. The process is continued to produce the desired element [34-36]. The upper layer is the furthest from the platform (see Figure 6, UH layer). Vertical direction does not affect the structure of the surfaces of the PLA or PLA/PHA blend because the contact with the printer platform was only at the small area at the base of the sample.

Tissue engineered scaffolds must have an appropriately organised and repeatable microstructure that allows the cells to be assembled in an ordered matrix that ensures the proper perfusion of nutrients. This is what $3 \mathrm{D}$ printing technology provides. 3D cylindrical scaffolds made of poly( $\varepsilon$-caprolactone) (PCL) were prepared using a bioplotter dispensing machine. In order to obtain a porous but sufficiently stiff $3 \mathrm{D}$ structure, the scaffold consisted of filament layers, which were extruded sequentially by the bioplotter with $0^{\circ} / 90^{\circ}$ pattern. The diameter of the filament $(200 \mu \mathrm{m})$ depended not only on the internal diameter of the nozzle $(250 \mu \mathrm{m})$ but also on the deposition speed (30$35 \mathrm{~mm} / \mathrm{min}$ ) (see Figure 7) [37].

SEM images allow not only to characterise the morphology of the 3D samples surface but also filament size or microorganism species.

\section{Microscopic Methods in Nanomaterial Characterisation}

Nanotechnology is one of the fastest growing interdisciplinary areas at present. Nanomaterials are mainly used in electronics, healthcare, cosmetics, construction, and automotive industries. Depending on the application, nanoparticles are divided into two main groups: organic and inorganic. Nanoparticles with inorganic base are fullerene, quantum dot, silica, and gold and with organic base are micelle, dendrimer, liposome, hybrid, nanosphere, and nanocapsule [39].

(Bio)degradable polymers are often used in the preparation of nanomaterials [40]. The applications of (bio)degradable polymeric nanomaterials have a wide range of usability in the field of therapeutics such as diagnostics, imaging, drug delivery, organ implant, tissue engineering, and in area of packaging materials [41]. The type of polymer system, area of applicability, and required particle size determine the type of (bio)degradable polymeric nanomaterials preparation.

The SEM/EDX technique is useful in the research in all works that require the determination of elements, endogenous or exogenous, in tissues, cells, etc., such as drugs delivery. The EDX helps in the detection of nanoparticles used to improve the therapeutic efficacy of certain chemotherapeutic agents. It is also used in the study of environmental pollution and in the characterisation of minerals bioaccumulated in the tissues [42]. Using SEM can be examined, for example, the fine nanoporous aerogels structure, in situ SEM methods investigating the thermal stability of nanoparticles such as graphene/Cu based materials, the effects of electron beam irradiation on the electrical properties of carbon nanotube yarns, and the nanoindentation work of multiphase thermoelectric material [43]. AFM is used to investigate the size and shape of nanoparticles in 3D mode, to assess the degree of surface coverage with nanoparticles, dispersion of nanoparticles in cells and other matrices/carriers, and precision in lateral dimensions of nanoparticles [44].

The most commonly applicable (bio)degradable polymers are PLA, poly(lactic-co-glicolic acid) (PLGA), and PHBV which themselves form particles or are used as part of copolymers or surface materials for inorganic particles. Biocompatible PLA-based micro- and nanoparticles are prepared by different techniques (Table 1), and the morphology of these nanoparticles is most often investigated by SEM.

PLGA is another widely used (bio)degradable polymer for nanoparticle preparation by the emulsification, solvent evaporation, and nanoprecipitation method [53]. By using various molar masses of PLGA $\left(M_{w}\right.$ of $14,500,45,000$, $85,000,137,000$, and $213,000 \mathrm{~g} / \mathrm{mol}$ ), particles were prepared with size $90-120 \mathrm{~nm}$. The prepared particles were studied as a drug release system [54].

The effect of various preparation conditions on the size and morphology of the PHBV micro- and nanoparticles for potential applications as reinforcement of $\mathrm{PHBV} / \mathrm{starch}$ matrices was examined using field emission SEM (see Figure 8 ). The spherical porous micro- and nanoparticles produced by the emulsification/solvent evaporation were with a size of 300 to $20 \mu \mathrm{m}$. It has been found that the size, porosity, and the particle size distribution can be controlled by the choice of surfactant and polymer concentration during the emulsification process, while choosing the appropriate antisolvent and adjusting its polarity were crucial for obtaining spherical particles through nanoprecipitation [55].

Studying the cell material interactions is crucial for collecting relevant information on the impact of structure and composition at the atomic and macromolecular level of bioinspired scaffolds. Thus, the assessment of the surface properties can be suitable technique in this regard. AFM has a significant impact on the in vitro studies of (bio)degradable materials produced in various forms, i.e., films, fibres, or nanoparticles for tissue engineering and drug delivery, capable of gradual resorption by ex novo formation of extracellular matrix with predefined structural/mechanical properties, similar to native tissues [56].

\section{Electrospun Eco-Friendly Polymer-Based Blends, Composites, and Hybrid Materials: Microscopic Examinations}

Electrospinning is considered as attractive procedure of forming ultra-fine fibres in a nano- and microscale into nonwoven mats due to its simplicity, cost effectiveness, and high rate of production. The schematic representation of the most common electrospinning setup is displayed in Figure 9. The advantage of electrospun nanofibres is mimicking of 

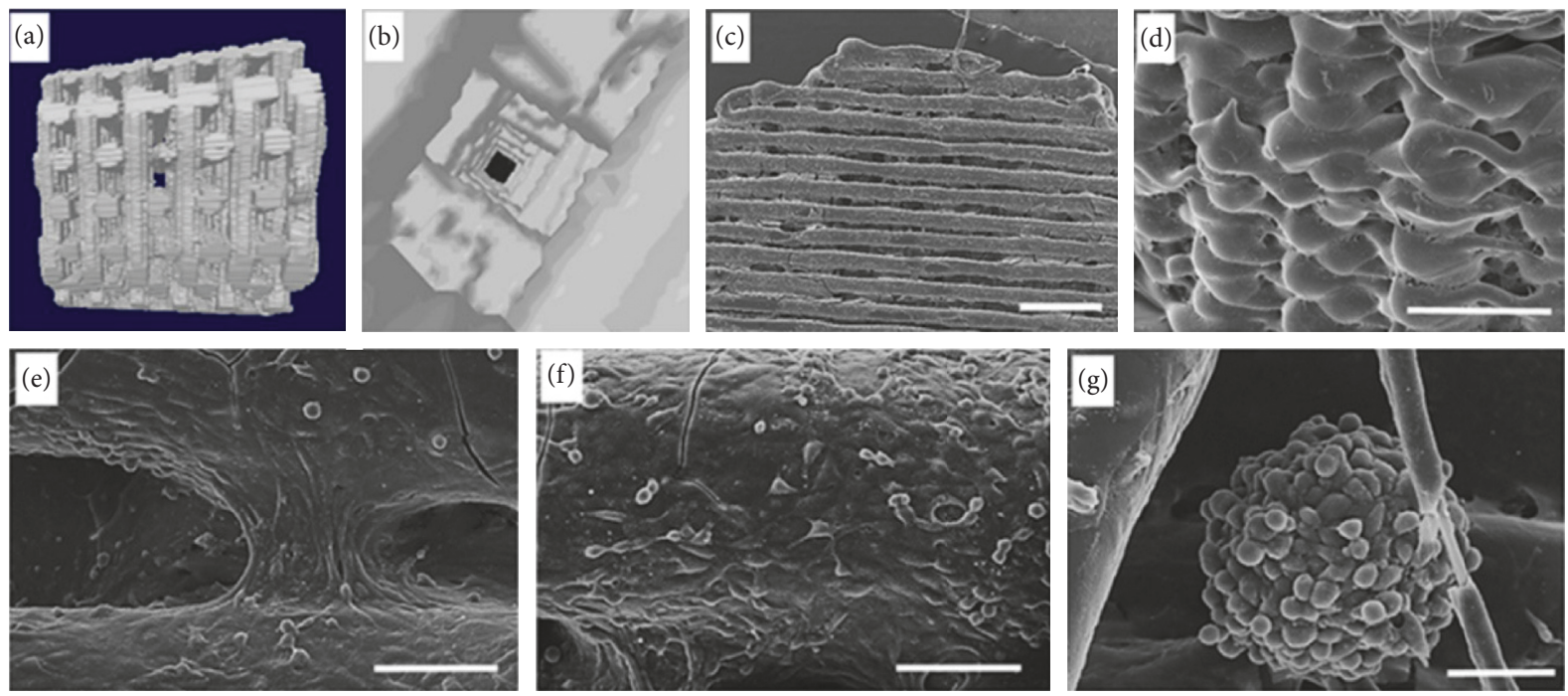

FiguRE 7: SEM micrographs: (a) lateral view of 3D filament-deposited scaffold reconstruction; (b) inner structure of the same scaffold; (c) colonisation of the 3D PCL scaffold in dynamic condition (scale bar $1 \mathrm{~mm}$ ); (d) high magnification showing the external cell monolayer (scale bar $1 \mathrm{~mm}$ ); (e) cells bridging the grooves (scale bar $100 \mu \mathrm{m}$ ); (f) cell arrangement suggestive of a new vascular structure (scale bar $100 \mu \mathrm{m}$ ); (g) spheroid of MC63 and human umbilical vein cells generated in dynamic condition (scale bar $50 \mu \mathrm{m})$ (adapted with permission from ref. [38]).

TABle 1: Preparation of PLA base (bio)degradable polymeric nanomaterials.

\begin{tabular}{lccc}
\hline Preparation techniques & Polymers & Size $(\mathrm{nm})$ & References \\
\hline Emulsion & PLA & 200 & {$[45]$} \\
Nanoprecipitation & Polydopamine-modified tocopheryl poly(ethylene & 126 & {$[46]$} \\
Dialysis & glycol succinate)-PLA (TPGS-PLA) & $90-330$ & $960-3000$ \\
Spray drying & PLA-poly(ethylene glycol)-PLA (PLA-PEG-PLA) & Micro & {$[47]$} \\
Melting technique & PLA & Micro & {$[49]$} \\
Supercritical fluids technique & PLA/PLGA & Micro & {$[50]$} \\
Microfluid technique & PLA & Micro & {$[51]$} \\
Template/mould based technique & PLA/ $\gamma$-Fe $\mathrm{O}_{3}$ & PLA & [52] \\
\hline
\end{tabular}
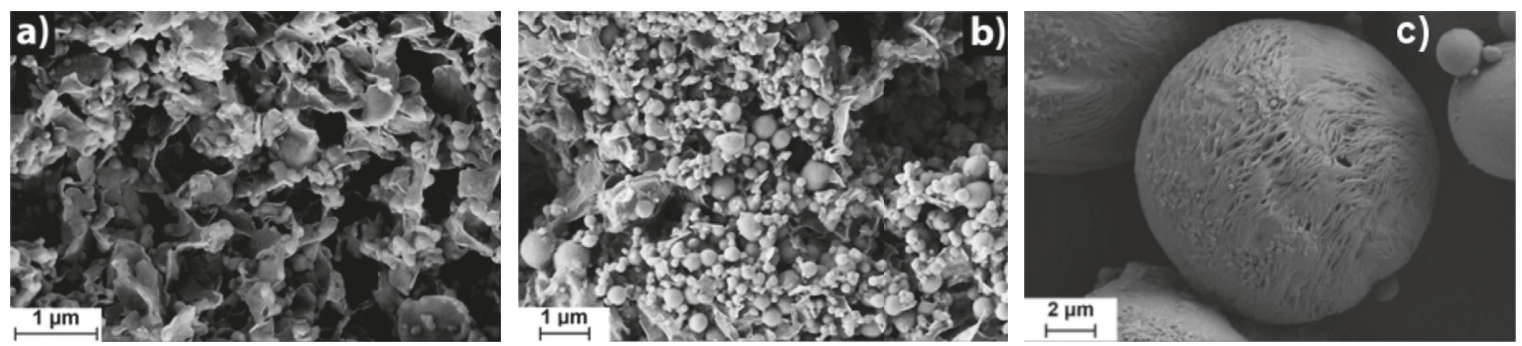

FIgURE 8: Micrographs of micro- and nanoparticles of PHBV prepared by nanoprecipitation method using 0.5\% PHBV in dimethylformamide (DMF) as solvent and water as antisolvent (a) and $0.1 \%$ PHBV in DMF as solvent and $10 \% \mathrm{NaCl}$ solution in water as antisolvent (b); microparticles of PHBV prepared by emulsification/solvent evaporation method using $1 \%$ PHBV in dichloromethane (DCM) and sodium dodecyl sulphate (SDS) as surfactant in a concentration of 1\% (c) (adapted with permission from ref. [55]).

three-dimensional structure of natural extracellular matrix, which predetermine them for biomedical and biotechnological application as tissue engineering, wound dressing, and drug release $[57,58]$. Besides this, it can be synthesised and tailored to suit a wide range of others applications including electronics $[59,60]$, environmental engineering $[61,62]$, agriculture $[63,64]$, and food packaging $[65,66]$.
The high customisation and easy functionalisation of the nanofibres offer numerous opportunities to control and to evaluate the morphology and/or chemical changes on the surface of blends, composites, and hybrids. SEM, transmission electron microscopy (TEM), and AFM may be valid tools for characterising surface topography and understanding the specific mechanical, chemical, and physical 


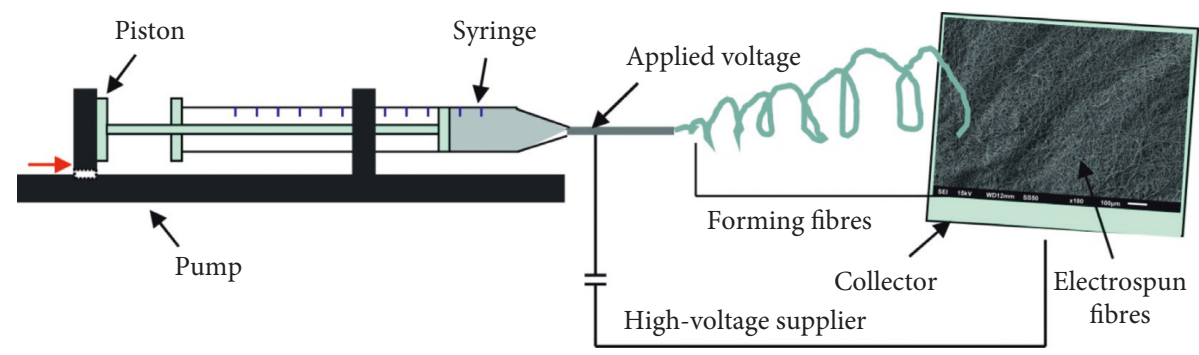

FiguRE 9: Schematic representation of conventional electrospinning setup to prepare electrospun nanofibres (archive of authors).

properties with regards to application of investigated materials $[56,67,68]$.

\subsection{Electrospinning Process Parameters of (Bio)degradable} Polymers. To date, many materials including natural polymers, synthetic polymers, and their mixture have been electrospun. Particularly, (bio)degradable polymers are used extensively in the biomaterial fields including polyesters, such as PLA, poly(glycolic acid) (PGA), PCL, PHB, or polyester copolymers, such as PLGA, PHBV, and PBAT $[63,69,70]$.

The parameters influencing the morphology and properties of electrospun fibres can be divided into solution parameters, process parameters, and ambient conditions. The most relevant parameters related to the solution properties are nature of used solvent, its dielectric properties, volatility, boiling point, the solution concentration, and molar masses of polymers that control the viscosity. Into the group of processing parameters belong flow rate through the needle, inner diameter of the needle, needle-to-collector distance, applied voltage, and geometry of collection (static collector or rotating drum). These parameters control the jet formation. The ambient conditions as ambient temperature, humidity, and air flow are influencing the morphology of the products as well $[57,71,72]$. After electrospinning, SEM is performed for morphological analysis generating SEM images, for measuring the fiber diameter, etc. SEM enables the optimisation of electrospinning process for preparation of continuous nanofibres with specific morphology and welldefined physical and mechanical properties, depending on the type of application of the mats.

Most of the studies concern the electrospinning parameters for (bio)degradable polymers trying to understand the electrospinning mechanism. PLA, PCL, and PHB and their blends in the form of nanofibres can be used in a wide variety of biomedical and biotechnological applications. PLA as well as PCL and PHB electrospinning process strongly depends from the type of polymer/solvent system. These (bio)degradable polymers are electrospun from the different single solvent system such as acetone, 2,2,2-trifluoroethanol (TFE), chloroform (TCM), and many others, and continuous fibres are obtained only using solvents with high electrical conductivity. Smooth defect-free nanofibres with a narrow and more homogenous diameter distribution are collected using binary solvent systems such as acetone/ DMF or acetone/dimethylacetamide (DMAc) (in the case of PLA) [72], tetrahydrofuran (THF)/methanol, DCM/DMF (in the case of PCL) $[73,74]$ (see Figure 10), and TCM/DMF (for electrospinning of PHB) [71].

In case of PCL electrospinning, the variable parameters such as single solvent system, DCM, binary solvent system DCM/DMF $1 / 1$, and concentrations $5 \mathrm{wt} . \%, 10 \mathrm{wt} . \%$, and 15 wt.\% of polymer solution were investigated, respectively.

(Bio)degradable copolymer PLGA was successfully electrospun from DCM and TCM but from hexafluoroisopropanol (HFIP) was generated the narrower fibre diameter distribution [75]. PHBV nanofibrous mats were generated from TCM [76]. Blend of two (bio)degradable polymers PLA and PBAT was electrospun, and the best solution for achieving the smooth fibres was the binary solvent DCM/DMF, but the proportion played an important role, and 3:2 was found as the most suitable [77]. Solution concentration which is closely related to viscosity also plays an important role in electrospinning. The increasing concentration leads to the increase of fibre diameters. Too small concentration prevents the nanofibres formation, and instead of fibres, only beads appear [78]. With regards to process parameters of electrospinning of (bio)degradable polymers, in general, at the higher voltage, the jet is unstable; therefore, more homogenous nanofibres at lower applied voltage are formed. In the case of PCL solution in HFIP, the smooth fibres are generated at $15 \mathrm{kV}$ compared to $25 \mathrm{kV}$ when the fibres with high average diameter are formed [79]. Tip to collector distance has a direct effect on the jet flight time and electric field strength. Fibres with small diameters can be formed when the working distance is greater. Reducing the distance shortens the time of jet flight, time of solvent evaporation, and electric field strength; all these conditions result in an increase of bead formation. On the contrary, a very large increase in the needle tip distance to the collector leads to an unstable jet and to beaded structured nanofibres [76].

The ambient conditions affect the morphology of the nanofibres observed by SEM. The collection procedure was studied by SEM. The average diameter of nanofibres collected on static collector was compared to the average diameter collected by rotating drum. The difference lies in directing of the fibres in the mats. From static collector was obtained mats with random placement of the fibre, whilst by rotating drum the aligned fibres in mats were collected. The average diameter of random $(559.04 \mathrm{~nm})$ and aligned PHB nanofibres $(675 \mathrm{~nm})$ was investigated, and it was shown that there were no significant differences in the diameters. On the other hand, the PLA is very sensitive on humidity. In the spinning process, solvent evaporates from charged jet, but 


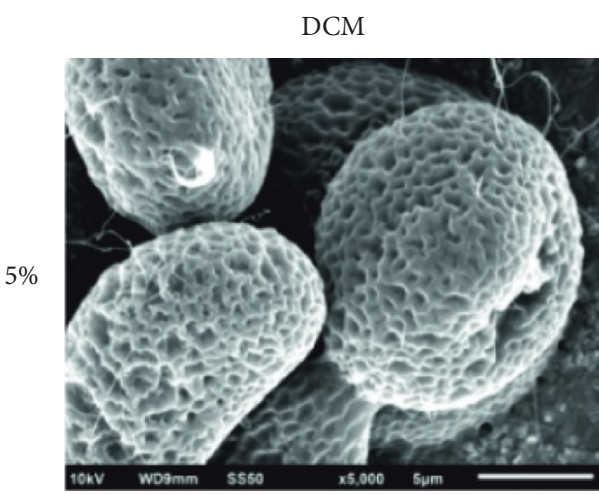

(a)

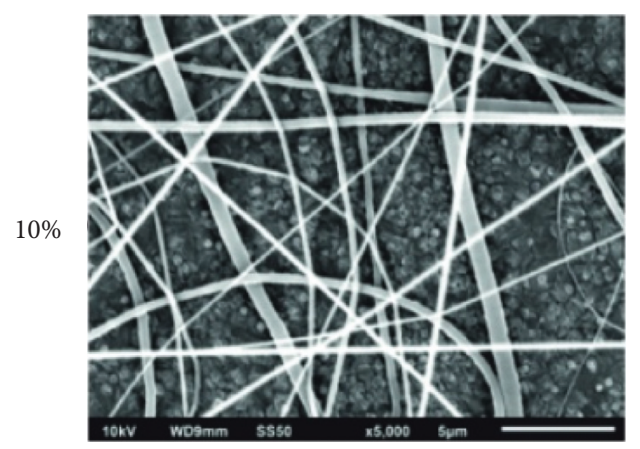

(c)

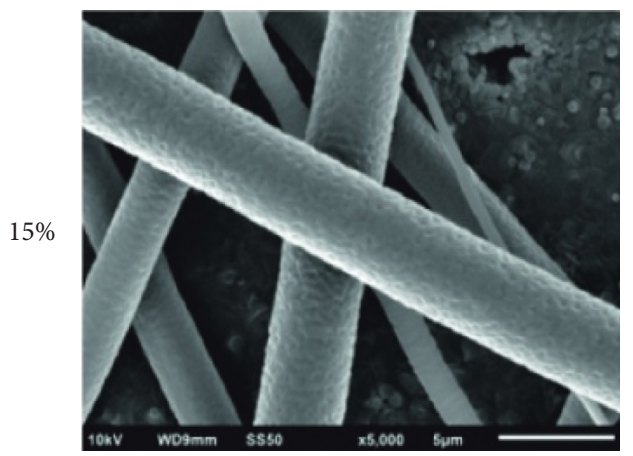

(e)
DCM/DMF $1 / 1$

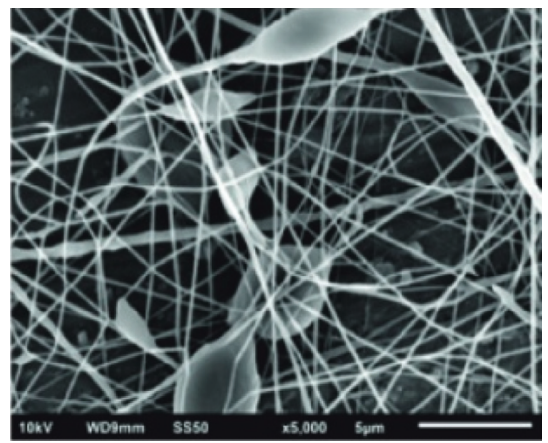

(b)

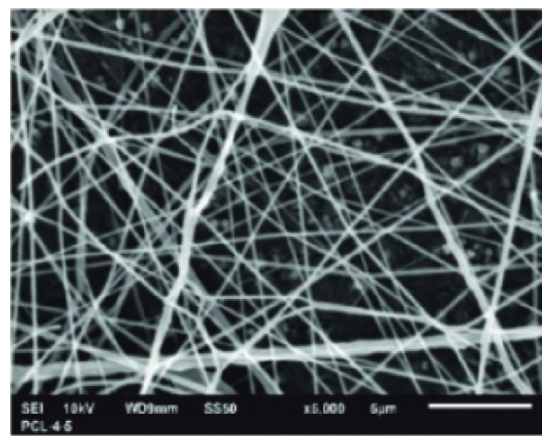

(d)

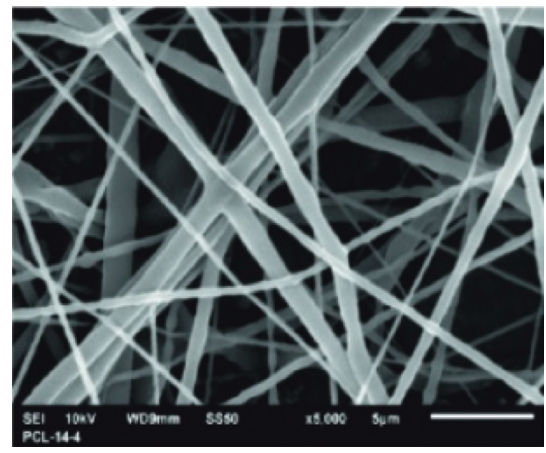

(f)

FIGURE 10: SEM micrographs of electrospun PCL at constant conditions: applied voltage $=10 \mathrm{kV}$, flow rate $=1 \mathrm{ml} / \mathrm{h}$, needle to collector distance $=15 \mathrm{~cm}$, and scale bar $=5 \mu \mathrm{m}$ (archive of authors).

water vapour occupies the position of the evaporated solvent. As a result, pores are formed on fibre surface after solidification of the polymeric phase (see Figure 11). The bigger pores formed at higher humidity due to more water vapour replacing the position of the evaporated solvent [80]. The electrospinning mechanism is difficult to understand due to lot of parameters. Microscopic examination enables to adjust the conditions to achieve the required morphology with regards to the application.

Highly porous PLA was electrospun into the liquid collector, hot water bath, at $70^{\circ} \mathrm{C}$. The $12 \mathrm{wt} . \%$ solutions were prepared by dissolving PLA pellets in TCM. The solution was stirred on a magnetic plate with intensity $615 \mathrm{rpm}$ for $2.5 \mathrm{~h}$. DMF was added to reach required concentrations and for enhanced properties of the solutions. The TCM/DMF ratio was set at 90/10 v/v. The parameters for electrospinning PLA were selected. The solution was electrospun from a
$5 \mathrm{~mL}$ syringe at the flow rate of $1.2 \mathrm{~mL} / \mathrm{h}$. Voltage of $12 \mathrm{kV}$ was applied; needle to collector distance was $15 \mathrm{~cm}$. The average diameter measured from SEM micrographs calculated by ImageJ software was $893 \pm 151 \mathrm{~nm}$.

4.2. Microscopic Investigation of Blends, Composites, and Hybrids Based on (Bio)degradable Polymers. Electrospun nanofibres are mimicking of structure of natural extracellular matrix, which predetermine them for application in biomedical field as wound dressing, tissue engineering, and drug release.

The fundamental requirements on the biomaterials used in biomedical field are biocompatibility, mechanical stability, and specific biological properties. Conventional single polymer materials cannot meet these requirements; therefore, multicomponent systems are designed and prepared. 

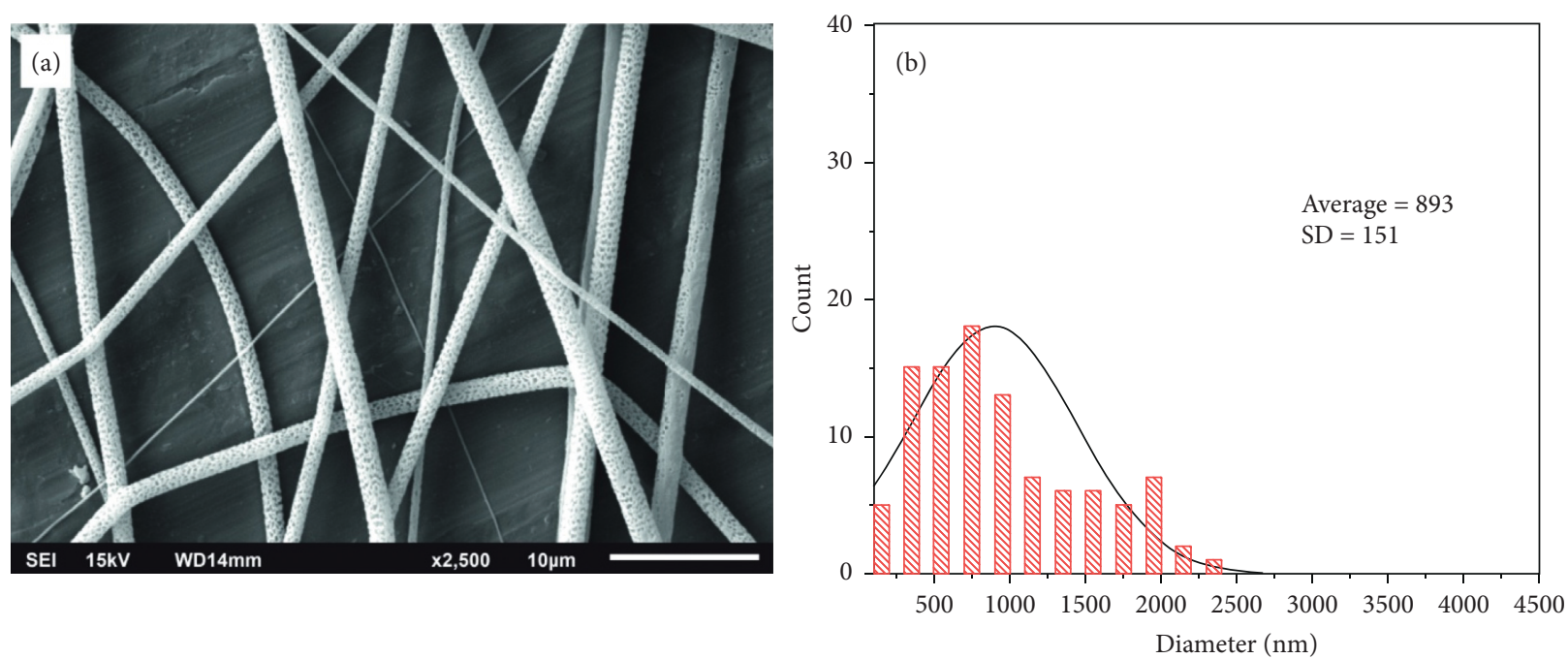

Figure 11: SEM micrographs of electrospun highly porous PLA (a) and histogram (b) (archive of authors).

Introduction of biomolecules or inorganic molecules into (bio)degradable polymer matrix is effective to obtain blends, composites, and hybrids with required properties [81].

4.2.1. Wound Healing Dressing. Porous electrospun nanofibrous matrices offer greater surface area and allow high oxygen permeation, easy protrusion of exudates, and protection of wounds from infection, bacterial colonisation, and dehydration. All these properties are important for wound healing dressing. For such application was tested composite containing starch and PCL, nanofibres, which was fabricated by coaxial needle electrospinning technique. Processing parameters such as polymer solution concentration, flow rate, the nozzle-ground distance, or applied voltage had a marked influence on the composite fibre diameter, and morphological study had an importance for the visualisation and understanding of the fibre structure. The SEM visualisation revealed that the PCL component in the electrospun nanocomposite structure was more prone to create fibres, while the starch formed beads. This was because of structural features of starch. Furthermore, a relationship between diameter of the fibres and concentration of starch was observed. The fibre diameter increased with the starch concentration because the bigger beads caused the formation of thicker fibres connecting these beads, also providing better strength. A lower diameter range of fibres was caused by both low viscosity and electrical conductivity, resulting in a low viscoelastic force. In general, a higher concentration of starch denoted the higher viscosity, fibre diameter, and bead formation [82]. In other study, the electrospun mats on the base of blends containing PHBV copolymer and collagen as well as gelatine, respectively, were examined as a biological wound dressing. SEM images showed cell morphology and attachment after in vitro culture of human dermal sheath (DS) cells in matrices. DS cells adhered significantly faster to the hydrophilic PHBV/collagen matrix than to hydrophobic PHBV matrix. Whilst DS cells achieved complete confluence into the hydrophilic matrix within 6 hours, at the same time, these cells were just beginning to attach to the hydrophobic matrix. Nevertheless, wound healing test results showed that the contribution of $\mathrm{PHBV} /$ collagen into the healing process was small, although it showed increase in hydrophilicity and faster hydration, better cell attachment, and proliferation compared to $\mathrm{PHBV}$, which was much more mechanically stable. These results indicated that mechanical stability of matrix is more important factor in wound healing than its cell culture activity [83].

4.2.2. Drug Delivery Systems. Electrospinning offers the opportunity to design new systems which act as a vehicle of local drug administration that can release the therapeutic agent at the site of the pathogenic area. Drug delivery on the base of polymer nanofibres is based on the principle that the drug dissolution rate increases with increased surface area. The nanofibrous membrane containing drug can be postprocessed into the kind of drug formulation [84].

Biomimetic fibrous scaffolds of PLA and PLA loaded with dipyridamole (DPM) were developed to act as drug delivery system coated on the cardiovascular stents [74]. The evaluation of the surface morphology and topography of PLA scaffold after fabrication, DPM loaded PLA system, coated stent, and delivery system during degradation process was conducted through AFM and SEM. Drug-loaded scaffolds were fabricated with good morphology without beads. The average diameter of blank PLA nanofibres $(522 \mathrm{~nm})$ and loaded PLA $(556 \mathrm{~nm})$ was calculated by ImageJ software on the basis of SEM images. The degradation study took 90 days, and how scaffolds degrade with hydrolysis was observed. Microscopic evaluation revealed the differences in average diameter of nanofibres. After 30 days, the diameters in both cases (blank and loaded PLA scaffolds) increased due to the swelling of the scaffolds, along the hydrophobicity of the polymer; then in 90 days, the degradation started due to hydrolysis and therefore the diameter decreased. Finally, the total amount of DPM loaded was released through scaffold after 218 days [74]. Electrospun mats for controlled release of 
paracetamol were also developed. The SEM study showed that the morphology of electrospun fibres was of a common nature, and they are round-shaped, bead free, randomly arrayed, fibrous, and highly porous mats. The paracetamol crystals were not detected on the surface of fibres. This indicated that the drug was incorporated into the structure of electrospun fibres homogenously. From SEM images, average diameters were calculated. Then, degradation profiles of fibrous mats were assessed by SEM. Compared to the fine fibres before incubation, the morphology during incubation changed significantly. The fibres after $24 \mathrm{~h}$ of incubation at $\mathrm{pH}$ 5.6 were swollen and curly, and the samples contained coexisting fibres and films. At $\mathrm{pH} 4$ after $24 \mathrm{~h}$ of incubation, only films were detected without any fibres evidence [77]. Drug delivery vehicles can be used also in food packaging with loaded various bactericide agents and compounds with antimicrobial and/or antifungal activity $[65,66]$.

4.2.3. Tissue Engineering. Tissue engineering or regenerative medicine uses the scaffolds to support the cells to regenerate new extracellular matrix which have been destroyed by diseases, injury, or congenital defects. Electrospinning provides 3D porous mats with high porosity and large surface area, mimicking extracellular matrix structure; therefore, they are considered an excellent candidate for use in regenerative medicine. The requirements for tissue engineering application are biocompatibility and (bio)degradability. Also, scaffold architecture affects cell binding significantly [58]. (Bio)degradable polymers are commonly used as biomaterials for bone repair. To date, PLA, PLGA, PCL, PGA, their blends, composites, and hybrids were investigated for tissue engineering because they meet the most criteria for this application [85]. The bone is a rigid and complex form containing fibrous organic matrix impregnated with inorganic minerals, such as calcium or phosphate. Inorganic minerals provide the hardness and toughness to tissue. For example, alternatively, interest has been paid to a hybrid from PCL fibrous scaffold in combination with silicate-containing hydroxyapatite (SiHA) microparticles to improve cell penetration [86]. The morphology and structure of fibres is important in controlling the adhesion and proliferation of cells; therefore, the surface was investigated by SEM and was characterised by presence of the fibres in micron scale for PCL-SiHA scaffolds. The cell viability, as a crucial issue for the clinical use of 3D scaffolds, was tested by human mesenchymal stem cells (hMSCs) for a sitespecific repair [87].

\subsubsection{Electronics and Bioelectronics Applications.}

Electrospinning is a popular method also in the field of sensing or electronics, in general. The (bio)degradable materials are preferred in this direction as well because many studies are focused on creating and investigating environmentally friendly conductive sensors for gases and volatile organic compounds based on (bio)degradable electrospun nanofibres. To design and fabricate of environmentally friendly conductive sensors in moistened environments, the (bio)degradable electrospun nanofibrous polymer blends containing polyaniline (PANi) and $\mathrm{PHB}$ [88], PANi and
PLA [89], PLGA, PCL and PANi [90] or composites containing silver ink, PCL and poly(glycerol sebacate) (PGS) for stretchable electronics [91], and electrospun PCL nanofibres modified by polypyrrole [60] have been used. Morphology of (bio)degradable nanofibrous layers mainly by SEM or TEM has been investigated. The quality of nanofibres in the sense of homogeneity/heterogeneity, the beads presence, directing of the nanofibres, average diameter of nanofibres, distribution of active compounds in the nanofibres structures or continuity of coatings, presence of agglomerates, and their size has been evaluated. SEM investigations showed that the conductivity of final products was influenced by the continuity of the coating $[60,91]$ and/or the distribution of the conductive substance $[89,90]$. The individual components could be distinguished within the fibres by TEM for their different electron density [88]. According the SEM images, the outgrowth and viability of cells in the samples after electrical stimulation were also assessed and thus the suitability of final product as a good candidate for electrical conductive scaffolds was determined [90].

\section{Conclusions}

The (bio)degradable plastics market is relatively new, but involves more and more products that have so far been obtained from nonbiodegradable conventional polymers and is divided mainly between PLA, starch blends, PCL, cellulose, poly(butylene succinate) (PBS), PHAs, and their blends. Advanced (bio)degradable polymer materials are considered for many new applications, e.g., as superconductors or engineering materials. Such materials are also regarded necessary in medical applications. The development of polymeric materials for new applications is therefore of great importance. However, efficient use requires basic research necessary to determine the relationship between the structure of such materials, properties, and mechanism of degradation. Although environmentally friendly polymers have gained much attention as possible substitutes for conventional plastics, factors that affect their durability are often difficult to investigate. Obtaining basic knowledge about these interactions will allow better targeting of innovative applications of advanced (bio)degradable polymeric materials and avoiding problems when using final products. Various techniques are used to analyse polymeric materials. The SEM and AFM techniques are an indispensable tool in studies of polymer blends, composites, and hybrid functional materials such as nanomaterials and characterisation of electrospun nanofibres.

For (bio)degradable polymers, microscopic techniques can provide an accurate scan of surface morphology and give detailed information on sample surfaces heterogeneity at nanometre resolution, providing information about morphological changes during, for example, processing or detecting the elasticity and viscosities of a sample in the case of different substrates or distinguishing polymer phase transition. In addition, microscopic techniques such as AFM or SEM can be used to characterise blend, composite, and hybrid materials in terms of mechanical, physical, thermal, and chemical properties [56]. 


\section{Conflicts of Interest}

The authors declare that there are no conflicts of interest regarding the publication of this article.

\section{Acknowledgments}

This work was supported by a Polish-Hungarian Joint Research Project "Controlled release and degradation studies of biodegradable aliphatic polyester derivatives based nanoparticles loaded with organic drug" (2017-2019) and a Polish-Slovak Joint Research Project "Predictive study under composting conditions of bioactive materials obtained by electrospinning" (2019-2021). The authors would like to thank VEGA 2-0135-19 and APVV 15-0545 projects for the support.

\section{References}

[1] R. P. Babu, K. O’Connor, and R. Seeram, "Current progress on bio-based polymers and their future trends," Progress in Biomaterials, vol. 2, no. 1, p. 8, 2013.

[2] S. Jurczyk, M. Musioł, M. Sobota et al., "(Bio)degradable polymeric materials for sustainable future-part 2: degradation studies of $\mathrm{P}(3 \mathrm{HB}-$ co-4HB)/cork composites in different environments," Polymers, vol. 11, no. 3, p. 547, 2019.

[3] M. Musioł, H. Janeczek, S. Jurczyk et al., "(Bio)degradation studies of degradable polymer composites with jute in different environments," Fibers and Polymers, vol. 16, no. 6, pp. 1362-1369, 2015.

[4] M. C. Areaa and H. Cheradame, "Paper aging and degradation: recent findings and research methods," BioResources, vol. 6, no. 4, pp. 5307-5337, 2011.

[5] B. Nowak, J. Pająk, and J. Karcz, "Biodegradation of pre-aged modified polyethylene films," in Scanning Electron Microscopy, V. Kazmiruk, Ed., IntechOpen, London, UK, 2012, https:// www.intechopen.com/books/scanning-electron-microscopy/ biodegradation-of-pre-aged-modified-polyethylene-films.

[6] K. Kersten, Sample Degradation During SEM Analysis: What Causes It and How to Slow Down the Process, ThermoFisher Scientific, Waltham, MA, USA, 2018, https://blog.phenomworld.com/sample-degradation-scanning-electron-micro scope-sem.

[7] NanoScience Instruents, Atomic Force Microscopy, 2019, https:// www.nanoscience.com/techniques/atomic-force-microscopy.

[8] Y. Kikkawa, T. Suzuki, T. Tsuge, M. Kanesato, Y. Doi, and H. Abe, "Phase structure and enzymatic degradation of poly(llactide)/atactic poly(3-hydroxybutyrate) blends: an atomic force microscopy study," Biomacromolecules, vol. 7, no. 6, pp. 1921-1928, 2006.

[9] C. Coluzza, M. Bicchieri, M. Monti, G. Piantanida, and A. Sodo, "Atomic force microscopy application for degradation diagnostics in library heritage," Surface and Interface Analysis, vol. 40, no. 9, pp. 1248-1253, 2008.

[10] U. Maver, T. Velnar, M. Gaberšček, O. Planinšek, and M. Finšgar, "Recent progressive use of atomic force microscopy in biomedical applications," TrAC Trends in Analytical Chemistry, vol. 80, pp. 96-111, 2016.

[11] H. Mason, Measuring Equipment Detects 3D Printing Defects, 2018, https://www.additivemanufacturing.media/products/ measuring-equipment-detects-3d-printing-defects.
[12] S. Thomas, R. Thomas, A. Zachariah, and R. Mishra, Microscopy Methods in Nanomaterials Characterization, Elsevier, Amsterdam, Netherlands, 2017.

[13] N. Chouhan, "Silver nanoparticles: synthesis, characterization and applications," in Silver Nanoparticles-Fabrication, Characterization and Applications, K. Maaz, Ed., IntechOpen, London, UK, 2018, https://www.intechopen.com/books/silvernanoparticles-fabrication-characterization-and-applications/silvernanoparticles-synthesis-characterization-and-applications.

[14] A. M. Al-Enizi, M. M. Zagho, and A. A. Elzatahry, "Polymerbased electrospun nanofibers for biomedical applications," Nanomaterials, vol. 8, no. 4, 2018.

[15] J. Zeng, X. Chen, X. Xu et al., "Ultrafine fibers electrospun from biodegradable polymers," Journal of Applied Polymer Science, vol. 89, no. 4, pp. 1085-1092, 2003.

[16] J. Rydz, K. Wolna-Stypka, G. Adamus et al., "Forensic engineering of advanced polymeric materials. Part 1-degradation studies of polylactide blends with atactic poly[(R,S)-3hydroxybutyrate] in paraffin," Chemical and Biochemical Engineering Quarterly, vol. 29, no. 2, pp. 247-259, 2015.

[17] J. Rydz, W. Sikorska, M. Musioł et al., "Degradation of PLAbased (nan)ocomposites in different environments," in Nanostructured Materials Application and Innovation Transfer, Nanoscience \& Nanotechnology, Issue 14, E. Balabanova and E. Mileva, Eds., pp. 109-111, BPS Ltd., Sofia, Bulgaria, 2014.

[18] C. Ha and W.-J. Cho, "Miscibility, properties, and biodegradability of microbial polyester containing blends," Progress in Polymer Science, vol. 27, no. 4, pp. 759-809, 2002.

[19] J. Rydz, W. Sikorska, M. Musioł, B. Zawidlak-Węgrzyńska, and K. Duale, "Sustainable future alternative: (bio)degradablepolymers for the environment," Chapter 11520, in Encyclopaedia of Renewable and Sustainable Materials, S. Hashmi and I. Choudhury, Eds., Elsevier, Amsterdam, Netherlands, 2020, In press.

[20] K. Zhao, X. Yang, G.-Q. Chen, and J.-C. Chen, "Effect of lipase treatment on the biocompatibility of microbial polyhydroxyalkanoates," Journal of Materials Science: Materials in Medicine, vol. 13, no. 9, pp. 849-854, 2002.

[21] G. G. Choi, H. W. Kim, and Y. H. Rhee, "Enzymatic and nonenzymatic degradation of poly (3-hydroxybutyrate-co-3hydroxyvalerate) copolyesters produced by Alcaligenes sp. MT-16," Journal of Microbiology, vol. 42, no. 4, pp. 346-352, 2004.

[22] E. Marten, R.-J. Müller, and W.-D. Deckwer, "Studies on the enzymatic hydrolysis of polyesters I. Low molecular mass model esters and aliphatic polyesters," Polymer Degradation and Stability, vol. 80, no. 3, pp. 485-501, 2003.

[23] C. M. Chan, L.-J. Vandi, S. Pratt et al., "Insights into the biodegradation of PHA/wood composites: micro- and macroscopic changes," Sustainable Materials and Technologies, vol. 21, Article ID e00099, 12 pages, 2019.

[24] O. Wilfred, H. Tai, R. Marriott et al., "Biodegradation of polylactic acid and starch composites in compost and soil," International Journal of Nano Research, vol. 1, no. 2, pp. 1-11, 2018.

[25] M. Musioł, W. Sikorska, H. Janeczek et al., “(Bio)degradable polymeric materials for a sustainable future-part 1. Organic recycling of PLA/PBAT blends in the form of prototype packages with long shelf-life," Waste Management, vol. 77, pp. 447-454, 2018.

[26] Y. Kikkawa, T. Suzuki, M. Kanesato, Y. Doi, and H. Abe, "Effect of phase structure on enzymatic degradation in poly(L-lactide)/ 
atactic poly(3-hydroxybutyrate) blends with different miscibility," Biomacromolecules, vol. 10, no. 4, pp. 1013-1018, 2009.

[27] A. Amor, N. Okhay, A. Guinault, G. Miquelard-Garnier, C. Sollogoub, and M. Gervais, "Combined compatibilization and plasticization effect of low molecular weight poly(lactic acid) in poly(lactic acid)/poly(3-hydroxybutyrate-co-3hydroxyvalerate) blends," eXPRESS Polymer Letters, vol. 12, no. 2, pp. 114-125, 2018.

[28] C. C. Sarath, R. A. Shanks, and S. Thomas, "Polymer blends," in Nanostructured Polymer Blends, S. Thomas, R. Shanks, and S. Chandran, Eds., pp. 1-13, Elsevier, Amsterdam, Netherlands, 2013.

[29] A. Sangroniz, A. Gonzalez, L. Martin, L. Irusta, M. Iriarte, and A. Etxeberria, "Miscibility and degradation of polymer blends based on biodegradable poly(butylene adipate- co-terephthalate)," Polymer Degradation and Stability, vol. 151, pp. 25-35, 2018.

[30] Y. Deng, C. Yu, P. Wongwiwattana, and N. L. Thomas, "Optimising ductility of poly(lactic acid)/poly(butylene adipate-co-terephthalate) blends through co-continuous phase morphology," Journal of Polymers and the Environment, vol. 26, no. 9, pp. 3802-3816, 2018.

[31] K. Kersten, How SEM Helps to Detect Additive Manufacturing Defects in a 3D-Printed Object, ThermoFisher Scientific, Waltham, MA, USA, 2018, https://blog.phenom-world.com/ sem-additive-manufacturing-3d-printing-defects.

[32] I. Chiulan, A. N. Frone, C. Brandabur, and D. M. Panaitescu, "Recent advances in 3D printing of aliphatic polyesters," Bioengineering, vol. 5, no. 1, p. 2, 2017.

[33] J. Gonzalez Ausejo, J. Rydz, M. Musioł et al., “A comparative study of three-dimensional printing directions: the degradation and toxicological profile of a PLA/PHA blend," Polymer Degradation and Stability, vol. 152, pp. 191-207, 2018.

[34] S. Daneshmand and C. Aghanajafi, "Description and modeling of the additive manufacturing technology for aerodynamic coefficients measurement," Strojniški vestnik-Journal of Mechanical Engineering, vol. 58, no. 2, pp. 125-133, 2012.

[35] K. G. J. Christiyan, U. Chandrasekhar, and K. Venkateswarlu, "A study on the influence of process parameters on the mechanical properties of 3D printed ABS composite," IOP Conference Series: Materials Science and Engineering, vol. 114, article 012109, 2016.

[36] J. Gonzalez Ausejo, J. Rydz, M. Musioł et al., “Three-dimensional printing of PLA and PLA/PHA dumbbell-shaped specimens of crisscross and transverse patterns as promising materials in emerging application areas: prediction study," Polymer Degradation and Stability, vol. 156, pp. 100-110, 2018.

[37] K. Kyriakidou, G. Lucarini, A. Zizzi et al., "Dynamic coseeding of osteoblast and endothelial cells on 3D polycaprolactone scaffolds for enhanced bone tissue engineering," Journal of Bioactive and Compatible Polymers, vol. 23, no. 3, pp. 227-243, 2008

[38] M. Orciani, M. Fini, R. Di Primio, and M. Mattioli-Belmonte, "Biofabrication and bone tissue regeneration: cell source, approaches, and challenges," Frontiers in Bioengineering and Biotechnology, vol. 5, no. 17, 15 pages, 2017.

[39] P. Dobson, H. Jarvie, and S. King, "Nanoparticle," in Encyclopedia Britannica, 2019, https://www.britannica.com/ science/nanoparticle.

[40] S. K. Mallapragada and B. Narasimhan, Handbook of Biodegradable Polymeric Materials and Their Applications, American Scientific Publishers, USA, 2005.
[41] A. Mahapatro and D. Singh, "Biodegradable nanoparticles are excellent vehicle for site directed in-vivo delivery of drugs and vaccines," Journal of Nanobiotechnology, vol. 9, no. 55, pp. 1-11, 2011.

[42] M. Scimeca, S. Bischetti, H. K. Lamsira, R. Bonfiglio, and E. Bonanno, "Energy Dispersive X-ray (EDX) microanalysis: a powerful tool in biomedical research and diagnosis," European Journal of Histochemistry, vol. 62, no. 1, article 2841, 2018.

[43] F. Solá, "Advanced electron microscopy techniques in nanomaterials characterization at NASA Glenn Research Center," in The Transmission Electron Microscope-Theory and Applications, K. Maaz, Ed., IntechOpen, London, UK, 2015, https://www. intechopen.com/books/the-transmission-electron-microscopetheory-and-applications/advanced-electron-microscopy-techniquesin-nanomaterials-characterization-at-nasa-glenn-research-cen.

[44] S. Mourdikoudis, R. M. Pallares, and N. T. K. Thanh, "Characterization techniques for nanoparticles: comparison and complementarity upon studying nanoparticle properties," Nanoscale, vol. 10, no. 27, pp. 12871-12934, 2018.

[45] M. Zambaux, F. Bonneaux, R. Gref, P. Maincent, E. Dellacherie, and M. J. Alonso, "Influence of experimental parameters on the characteristics of poly(lactic acid) nanoparticles prepared by a double emulsion method," Journal of Controlled Release, vol. 50, no. 1-3, pp. 31-40, 1998.

[46] D. Zhu, W. Tao, H. Zhang et al., "Docetaxel (DTX)-loaded polydopamine-modified TPGS-PLA nanoparticles as a targeted drug delivery system for the treatment of liver cancer," Acta Biomaterialia, vol. 30, pp. 144-154, 2016.

[47] K. Na, K. H. Lee, D. H. Lee, and Y. H. Bae, "Biodegradable thermo-sensitive nanoparticles from poly(l-lactic acid)/ poly(ethylene glycol) alternating multi-block copolymer for potential anti-cancer drug carrier," European Journal of Pharmaceutical Sciences, vol. 27, no. 2-3, pp. 115-122, 2006.

[48] F. X. Lacasse, P. Hildgen, and J. N. McMullen, "Surface and morphology of spray-dried pegylated PLA microspheres," International Journal of Pharmaceutics, vol. 174, no. 1-2, pp. 101-109, 1998.

[49] C. Wischke and S. P. Schwendeman, "Principles of encapsulating hydrophobic drugs in PLA/PLGA microparticles," International Journal of Pharmaceutics, vol. 364, no. 2, pp. 298-327, 2008.

[50] P. S. C. Sacchetin, A. R. Morales, Â. M. Moraes, and P. D. T. V. E. Rosa, "Formation of PLA particles incorporating $17 \alpha$-methyltestosterone by supercritical fluid technology," Journal of Supercritical Fluids, vol. 77, pp. 52-62, 2013.

[51] C.-Y. Liao and Y.-C. Su, "Formation of biodegradable microcapsules utilizing 3D, selectively surface-modified PDMS microfluidic devices," Biomedical Microdevices, vol. 12, no. 1, pp. 125-133, 2010.

[52] Y. Lu, M. Sturek, and K. Park, "Microparticles produced by the hydrogel template method for sustained drug delivery," International Journal of Pharmaceutics, vol. 461, no. 1-2, pp. 258-269, 2014.

[53] A. Kumari, S. K. Yadav, and S. C. Yadav, "Biodegradable polymeric nanoparticles based drug delivery systems," Colloids and Surfaces B: Biointerfaces, vol. 75, no. 1, pp. 1-18, 2010.

[54] G. Mittal, D. K. Sahana, V. Bhardwaj, and M. N. V. Ravi Kumar, "Estradiol loaded PLGA nanoparticles for oral administration: effect of polymer molecular weight and copolymer composition on release behavior in vitro and in vivo," Journal of Controlled Release, vol. 119, no. 1, pp. 77-85, 2007. 
[55] Y. Farrag, B. Montero, M. Rico, L. Barral, and R. Bouza, "Preparation and characterization of nano and micro particles of poly(3-hydroxybutyrate-co-3-hydroxyvalerate) (PHBV) via emulsification/solvent evaporation and nanoprecipitation techniques," Journal of Nanoparticle Research, vol. 20, no. 71, p. 17, 2018.

[56] M. Marrese, V. Guarino, and L. Ambrosio, "Atomic force microscopy: a powerful tool to address scaffold design in tissue engineering," Journal of Functional Biomaterials, vol. 8, no. 7, p. 20, 2017.

[57] A. Rogina, "Electrospinning process: versatile preparation method for biodegradable and natural polymers and biocomposite systems applied in tissue engineering and drug delivery," Applied Surface Science, vol. 296, pp. 221-230, 2014.

[58] S. Agarwal, J. H. Wendorff, and A. Greiner, "Use of electrospinning technique for biomedical applications," Polymer, vol. 49, no. 26 , pp. 5603-5621, 2008.

[59] S. Reich, M. Burgard, M. Langner et al., "Polymer nanofibre composite nonwovens with metal-like electrical conductivity," Flexible Electronics, vol. 2, no. 1, 2018.

[60] E. Č́́ková, M. Mičušík, A. Šišková, M. Procházka, P. Fedorko, and M. Omastová, "Conducting electrospun polycaprolactone/ polypyrrole fibers," Synthetic Metals, vol. 235, pp. 80-88, 2018.

[61] V. Thavasi, G. Singh, and S. Ramakrishna, "Electrospun nanofibers in energy and environmental applications," Energy \& Environmental Science, vol. 1, no. 2, pp. 205-221, 2008.

[62] A. Camire, J. Espinasse, B. Chabot, and A. Lajeunesse, "Development of electrospun lignin nanofibers for the adsorption of pharmaceutical contaminants in wastewater," Environmental Science and Pollution Research International, pp. 1-14, 2018.

[63] V. Buchholz, M. Molnar, H. Wang et al., "Protection of vine plants against esca disease by breathable electrospun antifungal nonwovens," Macromolecular Bioscience, vol. 16, no. 9, pp. 1391-1397, 2016.

[64] M. Noruzi, "Electrospun nanofibres in agriculture and the food industry: a review," Journal of the Science of Food and Agriculture, vol. 96, no. 14, pp. 4663-4678, 2016.

[65] Y. Liu, X. Liang, S. Wang, W. Qin, and Q. Zhang, "Electrospun antimicrobial polylactic acid/tea polyphenol nanofibers for food-packaging applications," Polymers, vol. 10, no. 5, pp. 561-575, 2018.

[66] T. Huang, Y. Qian, J. Wei, and C. Zhou, "Polymeric antimicrobial food packaging and its applications," Polymers, vol. 11, no. 3, 2019.

[67] M. Marrese, V. Cirillo, V. Guarino, and L. Ambrosio, "Shortterm degradation of bi-component electrospun fibers: qualitative and quantitative evaluations via AFM analysis," Journal of Functional Biomaterials, vol. 9, no. 2, p. 27, 2018.

[68] B. R. Neugirg, M. Burgard, A. Greiner, and A. Fery, "Tensile versus AFM testing of electrospun PVA nanofibers: bridging the gap from microscale to nanoscale," Journal of Polymer Science Part B: Polymer Physics, vol. 54, no. 23, pp. 2418-2424, 2016.

[69] W. Meng, Z.-C. Xing, K.-H. Jung et al., "Synthesis of gelatincontaining PHBV nanofiber mats for biomedical application," Journal of Materials Science: Materials in Medicine, vol. 19, no. 8, pp. 2799-2807, 2008.

[70] M. Mader, V. Jérôme, R. Freitag, S. Agarwal, and A. Greiner, "Ultraporous, compressible, wettable polylactide/polycaprolactone sponges for tissue engineering," Biomacromolecules, vol. 19, no. 5, pp. 1663-1673, 2018.

[71] D. M. Correia, C. Ribeiro, J. C. C. Ferreira et al., "Influence of electrospinning parameters on poly(hydroxybutyrate) electrospun membranes fiber size and distribution," Polymer Engineering \& Science, vol. 54, no. 7, pp. 1608-1617, 2014.

[72] R. Casasola, N. L. Thomas, A. Trybala, and S. Georgiadou, "Electrospun poly lactic acid (PLA) fibres: effect of different solvent systems on fibre morphology and diameter," Polymer, vol. 55, no. 18, pp. 4728-4737, 2014.

[73] S. Sarabi-Mianeji, J. Scott, and D. J. Y. S. Pagé, "Impact of electrospinning process parameters on the measured current and fiber diameter," Polymer Engineering \& Science, vol. 55, no. 11, pp. 2576-2582, 2015.

[74] V. Bakola, V. Karagkiozaki, A. R. Tsiapla et al., "Dipyridamole-loaded biodegradable PLA nanoplatforms as coatings for cardiovascular stents," Nanotechnology, vol. 29, no. 27, article 275101, 2018.

[75] Y. P. Chen, H. Y. Liu, Y. W. Liu, T. Y. Lee, and S. J. Liu, "Determination of electrospinning parameters' strength in poly(D,L)-lactide-co-glycolide micro/nanofiber diameter tailoring," Journal of Nanomaterials, vol. 2019, Article ID 2626085, 8 pages, 2019.

[76] H.-W. Tong and M. Wang, "Electrospinning of poly(hydroxybutyrate-co-hydroxyvalerate) fibrous scaffolds for tissue engineering applications: effects of electrospinning parameters and solution properties," Journal of Macromolecular Science, Part B, vol. 50, no. 8, pp. 1535-1558, 2011.

[77] S. Khatsee, D. Daranarong, W. Punyodom, and P. Worajittiphon, "Electrospinning polymer blend of PLA and PBAT: electrospinnability-solubility map and effect of polymer solution parameters toward application as antibioticcarrier mats," Journal of Applied Polymer Science, vol. 135, no. 28, article 46486, 2018.

[78] R. Augustine, N. Kalarikkal, and S. Thomas, "Clogging-free electrospinning of polycaprolactone using acetic acid/acetone mixture," Polymer-Plastics Technology and Engineering, vol. 55, no. 5, pp. 518-529, 2015.

[79] M. I. Hassan, T. Sun, and N. Sultana, "Fabrication of nanohydroxyapatite/poly(caprolactone) composite microfibers using electrospinning technique for tissue engineering applications," Journal of Nanomaterials, vol. 2014, Article ID 209049, 7 pages, 2014.

[80] Z. Liu, J. Zhao, W. Li, J. Xing, L. Xu, and J. He, "Humidityinduced porous poly(lactic acid) membrane with enhanced flux for oil-water separation," Adsorption Science \& Technology, pp. 1-12, 2018.

[81] Z. C. Xing, S. J. Han, Y. S. Shin, and I. K. Kang, "Fabrication of biodegradable polyester nanocomposites by electrospinning for tissue engineering," Journal of Nanomaterials, vol. 2011, Article ID 929378, 18 pages, 2011.

[82] B. Komur, F. Bayrak, N. Ekren et al., "Starch/PCL composite nanofibers by co-axial electrospinning technique for biomedical applications," Biomedical Engineering Online, vol. 16, no. 1, p. 40, 2017.

[83] I. Han, K. J. Shim, J. Y. Kim et al., "Effect of poly(3hydroxybutyrate-co-3-hydroxyvalerate) nanofiber matrices cocultured with hair follicular epithelial and dermal cells for biological wound dressing," Artificial Organs, vol. 31, no. 11, pp. 801-808, 2007.

[84] M. Qi, X. Li, Y. Yang, and S. Zhou, "Electrospun fibers of acidlabile biodegradable polymers containing ortho ester groups for controlled release of paracetamol," European Journal of Pharmaceutics and Biopharmaceutics, vol. 70, no. 2, pp. 445-452, 2008.

[85] R. Kroeze, M. Helder, L. Govaert, and T. Smit, "Biodegradable polymers in bone tissue engineering," Materials, vol. 2, no. 3, pp. 833-856, 2009. 
[86] S. Shkarina, R. Shkarin, V. Weinhardt et al., "3D biodegradable scaffolds of polycaprolactone with silicate-containing hydroxyapatite microparticles for bone tissue engineering: high-resolution tomography and in vitro study," Scientific Reports, vol. 8, no. 8907, p. 13, 2018.

[87] Z. Sheikh, S. Najeeb, Z. Khurshid, V. Verma, H. Rashid, and M. Glogauer, "Biodegradable materials for bone repair and tissue engineering applications," Materials, vol. 8, no. 9, pp. 5744-5794, 2015.

[88] A. Macagnano, V. Perri, E. Zampetti, A. Bearzotti, and F. De Cesare, "Humidity effects on a novel eco-friendly chemosensor based on electrospun PANi/PHB nanofibres," Sensors and Actuators B: Chemical, vol. 232, pp. 16-27, 2016.

[89] P. S. Picciani, E. Medeiros, E. Venancio, B. Soares, and L. C. Mattoso, "Development of electrospun polyaniline/ poly(lactic acid) nanofiber-based sensors," Sensor Letters, vol. 14, no. 9, pp. 864-871, 2016.

[90] H. Farkhondehnia, M. Amani Tehran, and F. Zamani, "Fabrication of biocompatible PLGA/PCL/PANI nanofibrous scaffolds with electrical excitability," Fibers and Polymers, vol. 19, no. 9, pp. 1813-1819, 2018.

[91] A. H. Najafabadi, A. Tamayol, N. Annabi et al., "Biodegradable nanofibrous polymeric substrates for generating elastic and flexible electronics," Advanced Materials, vol. 26, no. 33, pp. 5823-5830, 2014. 


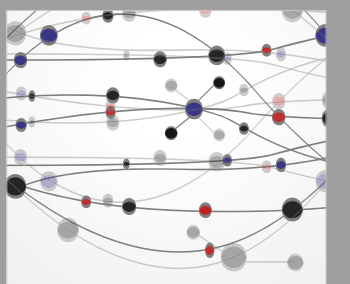

The Scientific World Journal
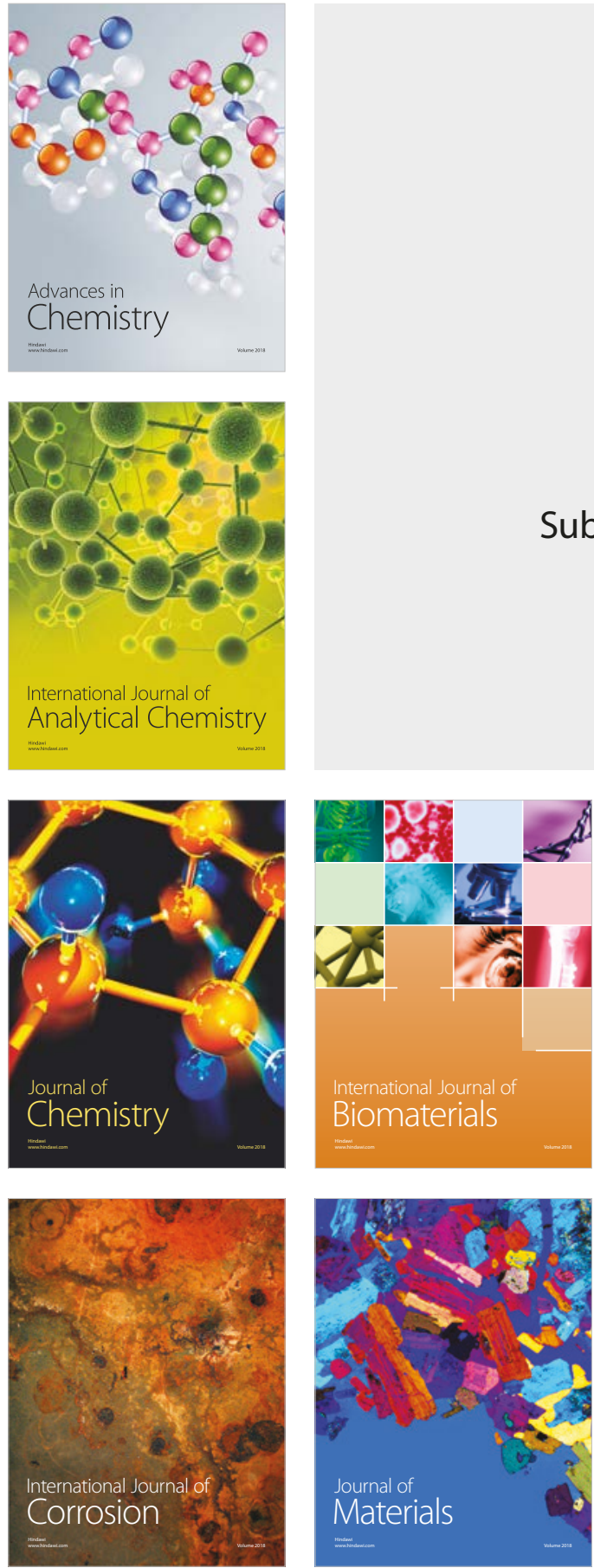

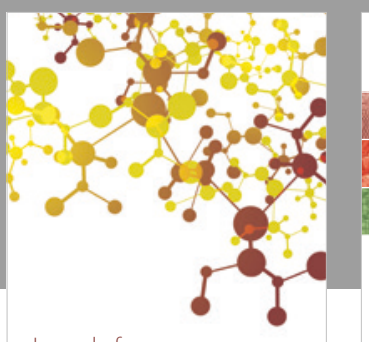

Journal of

Applied Chemistry
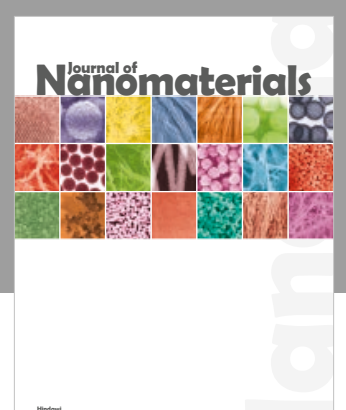

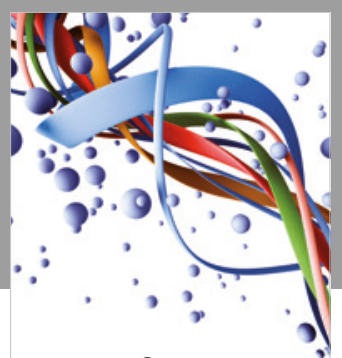

Scientifica

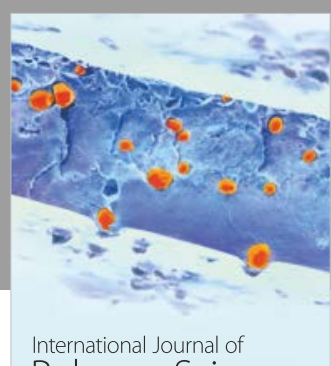

Polymer Science

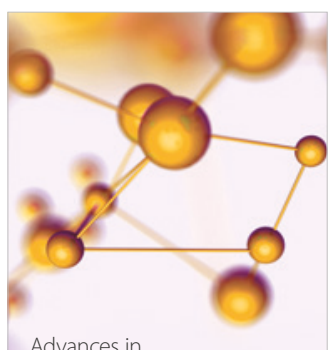

Physical Chemistry
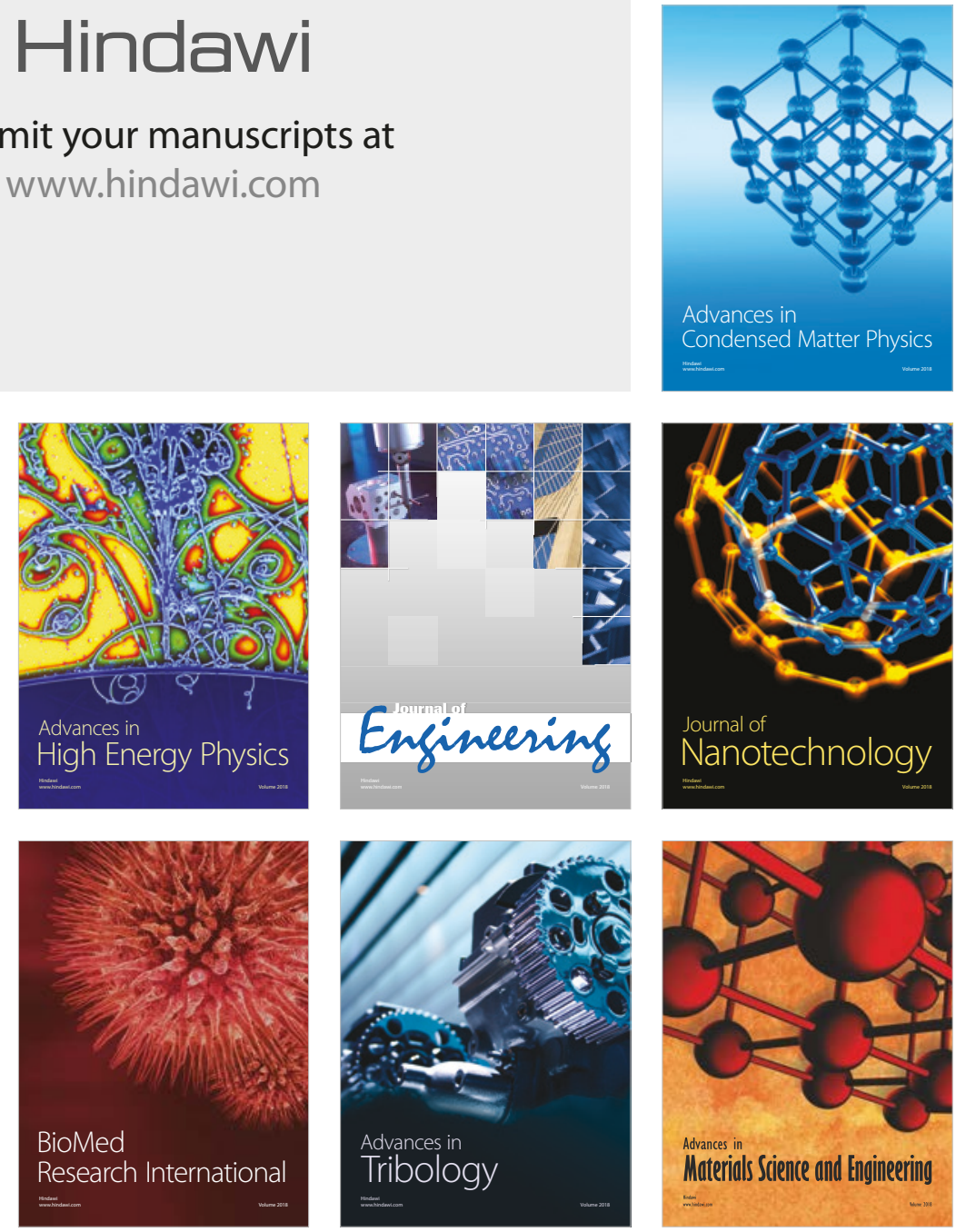